\title{
Review Article \\ Meso-/Nanoporous Semiconducting Metal Oxides for Gas Sensor Applications
}

\author{
Nguyen Duc Hoa, ${ }^{1}$ Nguyen Van Duy, ${ }^{1}$ Sherif A. El-Safty, ${ }^{2}$ and Nguyen Van Hieu ${ }^{1}$ \\ ${ }^{1}$ International Training Institute for Materials Science (ITIMS), Hanoi University of Science and Technology (HUST), \\ No. 1 Dai Co Viet Street, Hanoi, Vietnam \\ ${ }^{2}$ National Institute for Materials Science, 1-2-1 Sengen, Tsukuba, Ibaraki 305-0047, Japan
}

Correspondence should be addressed to Nguyen Duc Hoa; ndhoa@itims.edu.vn and Nguyen Van Hieu; hieu@itims.edu.vn

Received 10 December 2014; Revised 18 April 2015; Accepted 23 April 2015

Academic Editor: Peng Gao

Copyright (c) 2015 Nguyen Duc Hoa et al. This is an open access article distributed under the Creative Commons Attribution License, which permits unrestricted use, distribution, and reproduction in any medium, provided the original work is properly cited.

\begin{abstract}
Development and/or design of new materials and/or structures for effective gas sensor applications with fast response and high sensitivity, selectivity, and stability are very important issues in the gas sensor technology. This critical review introduces our recent progress in the development of meso-/nanoporous semiconducting metal oxides and their applications to gas sensors. First, the basic concepts of resistive gas sensors and the recent synthesis of meso-/nanoporous metal oxides for gas sensor applications are introduced. The advantages of meso-/nanoporous metal oxides are also presented, taking into account the crystallinity and ordered/disordered porous structures. Second, the synthesis methods of meso-/nanoporous metal oxides including the softtemplate, hard-template, and temple-free methods are introduced, in which the advantages and disadvantages of each synthetic method are figured out. Third, the applications of meso-/nanoporous metal oxides as gas sensors are presented. The gas nanosensors are designed based on meso-/nanoporous metal oxides for effective detection of toxic gases. The sensitivity, selectivity, and stability of the meso-/nanoporous gas nanosensors are also discussed. Finally, some conclusions and an outlook are presented.
\end{abstract}

\section{Introduction}

Air pollution caused by toxic, flammable, and explosive gases, such as $\mathrm{CO}, \mathrm{H}_{2} \mathrm{~S}, \mathrm{NH}_{3}, \mathrm{NO}_{2}, \mathrm{CH}_{4}, \mathrm{C}_{3} \mathrm{H}_{8}$, and $\mathrm{H}_{2}$, is one of the critical factors that contribute to global warming, climate change, and harm to human health [1-10]. Development and fabrication of a device for early detection and/or alarm of certain flammable, explosive, and toxic gases are extremely necessary. For this purpose, gas sensors have been invented and developed toward tract detection and/or concentration monitoring of such pollution gases $[3,4]$. Gas sensors are devices that detect and/or measure the track or concentration of analytic gaseous agents. However, the sensing device has difficulty in measuring or screening the analytic gas molecules directly; hence, the measured signals are usually converted into the change/variation in physical and/or chemical quantities, such as temperature, conductivity, frequency, capacitance, color, or pressure. According to the working principle of devices and/or the analytic species, gas sensors can be classified into different types. Based on (i) the working principle, the kinds of gas sensors include the capacitance, solid electrolyte, acoustic wave, and resistive types; (ii) analytic agents can process volatile organic compounds (VOCs), explosive or toxic gas sensor classification. Scheme 1(a) illustrates a general gas sensor, in which the adsorption of gaseous molecules to the sensing materials leads to the change in readout signals. Generally, any change in physical or chemical properties of materials upon gaseous molecule exposures can also be used as significant response of gas sensors. In practical applications, physical or chemical changes are usually converted into measureable or electrical signals through a transducer for easy measurements $[5,6]$. The human nose is an example of a sensitive gas sensor that can detect odor gases, such as $\mathrm{H}_{2} \mathrm{~S}, \mathrm{NH}_{3}$, and VOCs. However, it cannot detect certain odorless gas such as $\mathrm{CO}$, $\mathrm{CO}_{2}$, and $\mathrm{H}_{2}$. Despite the different gas sensors that have been developed, such as optical sensors, electrochemical sensors, calorimetric sensors, and resistive sensors, the most common 


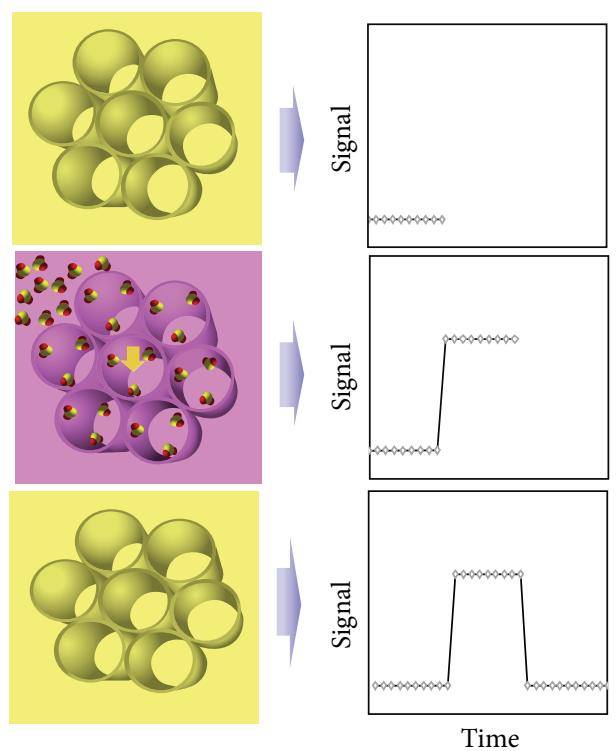

(a)

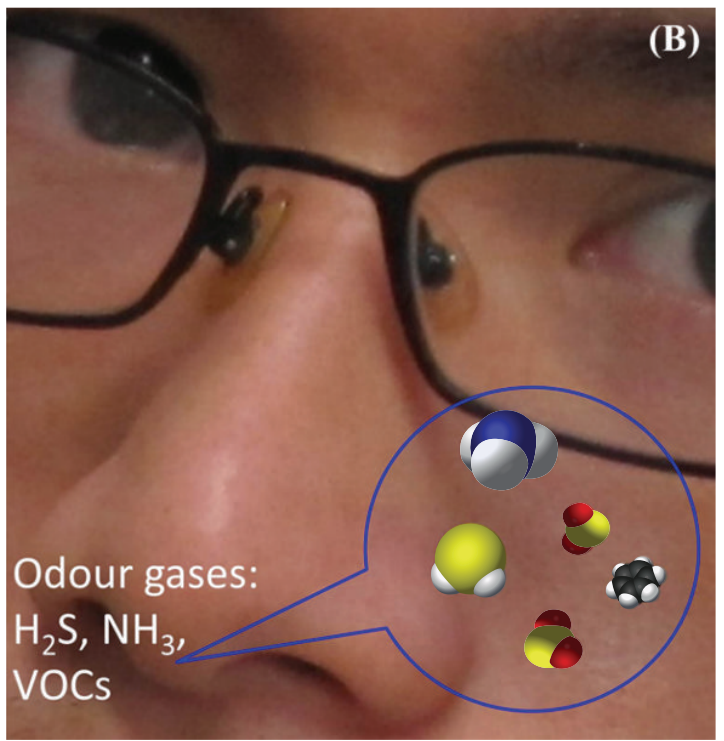

(b)

Scheme 1: (a) Carton of a general gas sensor, in which the adsorption of gaseous molecules to the sensing materials leads to the change in readout signals (physical or chemical properties). (b) A nose as an odor gas sensor.

and simplest gas sensor remains to be the resistive type [110]. The operation of this type of gas sensor is based on the change in electrical conductance (resistance) of the sensing materials upon gaseous molecule exposures. However, the low sensitivity, slow recovery, poor selectivity, and high working temperature of the bulk, thin, or thick films metal oxide-based gas sensors limit their potential applications. Our recent studies have been dedicated to the development of novel nanostructures for high performance gas sensors with high sensitivity, fast response/recovery time, and good selectivity [3-6].

Metal Oxide-Based Resistive Gas Sensors. In the early 1960s, Seiyama and Taguchi introduced the gas sensors that are operated based on variation in their electrical resistance (conductance) upon a chemical reaction and/or adsorption between the analytical gas species and the surface of metal oxide semiconducting layers $[1,2]$. Since then, investigations on resistive gas sensors have received a great deal of attention because of their low cost, simple completion, online-monitoring, and good reliability for real-time control systems, as well as their diverse practical applications in environmental monitoring, transportation, security, defense, space missions, energy, agriculture, and medicine [1-24]. Various metal oxide semiconductors with different geometrical structures, such as nanoplates, thin film, nanoparticles, nanorods, nanotubes [7], nanofibers [8], nanowires, and hollow spheres $[9,10]$, have been developed for gas sensor applications. Both p-type and n-type semiconductors [3-16] have been applied for detection of different gases, such as $\mathrm{C}_{2} \mathrm{H}_{5} \mathrm{OH}$ [17], $\mathrm{NO}, \mathrm{NH}_{3}$ [18], $\mathrm{CO}$ [19], $\mathrm{H}_{2} \mathrm{~S}$ [20], $\mathrm{O}_{3}$ [21], and $\mathrm{NO}_{2}$ [22-24]. Wide bandgap metal oxide semiconductors such as $\mathrm{ZnO}, \mathrm{SnO}_{2}, \mathrm{WO}_{3}, \mathrm{In}_{2} \mathrm{O}_{3}$, and $\mathrm{CuO}$ are commonly used as sensing materials in resistive gas sensors because of their high sensitivity to different gases [1-27]. Recently, reduction in the size of the device, miniaturization of production expense, and improvement of sensor performances for rapid response and high sensitivity, selectivity, stability, and feasibility have gained significant interests in the field of gas sensor technology. Moreover, development and exploration of new materials, structures, and geometries for effective gas sensor applications are of extreme interests $[25,26]$. Gao et al. prepared the $\mathrm{ZnO}$ materials of different morphologies such as nanorod arrays, nanoribbon bundles, nanosheets, nanocubes, and nanoparticles [27]. They also used the $\mathrm{ZnO}$ nanorods and hollow spheres for ethanol sensors, where the porous structure of hollow spheres showed a better gas sensing characteristic compared with the nanorods [26]. Studies on the synthesis and application of meso-/nanoporous materials to gas sensors are also increasing [22-24]. This highlight review focuses on mesoporous metal oxides, from synthesis to effective gas sensor applications. The use of mesoporous metal oxides for gas sensor applications has some advantages in enhancing sensor performance through total exposure of sensing sites to the analytic gases.

Meso-/Nanoporous Metal Oxides Based Resistive Gas Sensors. Nanostructures of meso-/nanoporous semiconducting metal oxides with large specific surface area are ideal materials for improving gas sensing performances by enhancing sensing sites and total exposures to analytical gases [2224]. According to their working principles, the responses of metal oxide-based gas sensors are dependent on various parameters, such as (i) the density and mobility of the main carriers, (ii) surface modification, (iii) grain size effects, and (iv) specific surface area and surface chemical properties of the materials [28-31]. The two former parameters are controlled by the type of sensing materials (free electron in 


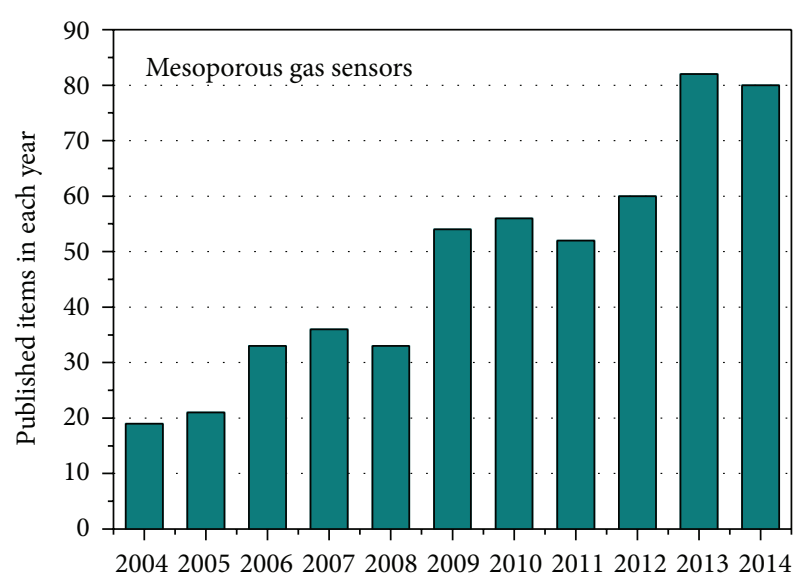

FIGURE 1: Recent reports on the mesoporous gas sensors (source: web of science core collection).

n-type and hole in p-type semiconductors) and the doping elements $[3,4,20]$. By contrast, the latter two (iii and iv) are dependent on the morphologies, shape, and size of materials and can be controlled through the fabrication of nanostructured meso-/nanoporous materials [9, 10, 22-24]. Essentially, nanostructured meso-/nanoporous materials with nanosize crystals and superior specific surface area could accelerate the gaseous adsorption/desorption processes during gas sensing measurements because such processes occur mainly on the surface of the sensing materials [31]. Therefore, the use of nanostructured meso-/nanoporous materials to improve gas sensor performances is of advantage [32]. In recent years, investigation on the synthesis and application of meso-/ nanoporous semiconducting metal oxides to gas sensors has gained increasing attention [33]. The number of reports on the mesoporous gas sensors has increased exponentially since 2004, as shown in Figure 1 (source: web of science core collection).

Taking into account the synthesis processes, meso-/ nanoporous metal oxides can be fabricated by soft- or hard-template methods. The soft-template method [34] uses polymer surfactants as structure guide agents in controlling the mesoporous structures, whereas the hard-template [35] applies preformed meso-/nanoporous materials as structure guide. Normally, the soft-template is a direct-synthesis, whereas the hard-template is often undirected. To date, both soft- and hard-template methods have been applied to synthesis of mesoporous metal oxides and their composites for gas sensor applications, despite their advantages and disadvantages compared with other methods [34-44].

\section{Synthesis of Meso-/Nanoporous Metal Oxides}

2.1. Soft-Template Synthesis of Meso-/Nanoporous Metal Oxides. The most commonly used method for directsynthesis of mesoporous metal oxides is the use of polymer surfactants as soft-templates [31]. This method utilizes the structure of the polymers as a structure-direct agent for fabrication of mesoporous metal oxides, which is very effective, specifically for synthesis of highly ordered mesoporous silica. Figure 2 illustrates the soft-template synthesis of ordered mesoporous metal oxides. Typical synthesis involves the wet chemical processes (sol-gel and hydrothermal) for selfassembly of surfactant and metal precursors to form the hybrid of metal oxides and polymers, followed by template removal.

However, the as-synthesized materials were amorphous phases or hybrid of metal oxides and polymers. After calcination at high temperature, the amorphous phases became semicrystalline or crystalline. However, the porous structure was distorted, leading to lower specific surface area [34]. Yang et al. reported on the generalized direct syntheses of large-pore mesoporous metal oxides, including $\mathrm{TiO}_{2}, \mathrm{ZrO}_{2}$, $\mathrm{Al}_{2} \mathrm{O}_{3}, \mathrm{Nb}_{2} \mathrm{O}_{5}, \mathrm{Ta}_{2} \mathrm{O}_{5}, \mathrm{WO}_{3}, \mathrm{HfO}_{2}$, and $\mathrm{SnO}_{2}$, and mixed oxides $\mathrm{SiAlO}_{3.5}, \mathrm{SiTiO}_{4}, \mathrm{ZrTiO}_{4}, \mathrm{Al}_{2} \mathrm{TiO}_{5}$, and $\mathrm{ZrW}_{2} \mathrm{O}_{8}$ [34]. The syntheses used amphiphilic poly (alkylene oxide) block copolymers as soft-template structure-directing agents in nonaqueous solutions to organize the network-forming metal oxide species. The results exhibited ordered mesoporous oxides containing nanocrystalline domains within thick amorphous walls. Cheng et al. reported on the synthesis of mesoporous tungsten oxide thin film using triblock copolymer P123 as structure-directing agent [36]. The synthesis involved the sol-gel processes for thin film formation, solvent extraction, and/or calcination to remove the copolymer template. The mesoporous metal oxides fabricated by directsynthesis method have also been applied to gas sensors fabrication. Sun et al. reported on the synthesis of mesoporous $\alpha-\mathrm{Fe}_{2} \mathrm{O}_{3}$ nanostructures for gas sensor applications, in which the $\alpha-\mathrm{Fe}_{2} \mathrm{O}_{3}$ was synthesized by the soft-template synthesis method using the triblock copolymer F127 surfactant [37]. The synthesized $\alpha-\mathrm{Fe}_{2} \mathrm{O}_{3}$ material has a disordered mesoporous structure with a specific surface area of $128 \mathrm{~m}^{2} \mathrm{~g}^{-1}$ and a pore size of about $7 \mathrm{~nm}$. The gas sensing properties of synthesized mesoporous $\alpha-\mathrm{Fe}_{2} \mathrm{O}_{3}$ were investigated for detection of flammable, toxic, and corrosive gases, such as ethanol, acetone, gasoline, heptane, formaldehyde, acetic acid, 1-butanol, and 2-propanol. Our recent work reported on the synthesis of mesoporous $\mathrm{WO}_{3}$ through an instant directtemplate method [38]. The F108 polymer surfactant was utilized as soft-template for the synthesis, similar to the conventional synthesis of mesoporous silica. However, the polymer template was converted into carbon by annealing in an inert gas $\left(\mathrm{N}_{2}\right)$ at high temperature to maintain the porous structure of materials before the removing of the soft-template by calcination in the air. The synthesized $\mathrm{WO}_{3}$ materials have good porosity and high crystallinity, but disordered porous structures (Figure 3). The soft-template directed syntheses of meso-/nanoporous metal oxides have been investigated for gas sensors applications; however, the disordered porous structures and low crystallinity of the prepared materials have limitations and drawbacks that should be addressed to improve the gas sensing performances of rapid response, high sensitivity, and long-term stability [31,34].

2.2. Hard-Template Synthesis of Meso-/Nanoporous Metal Oxides. Hard-template synthesis of nanostructured materials has been well known since the introduction of the synthesis 


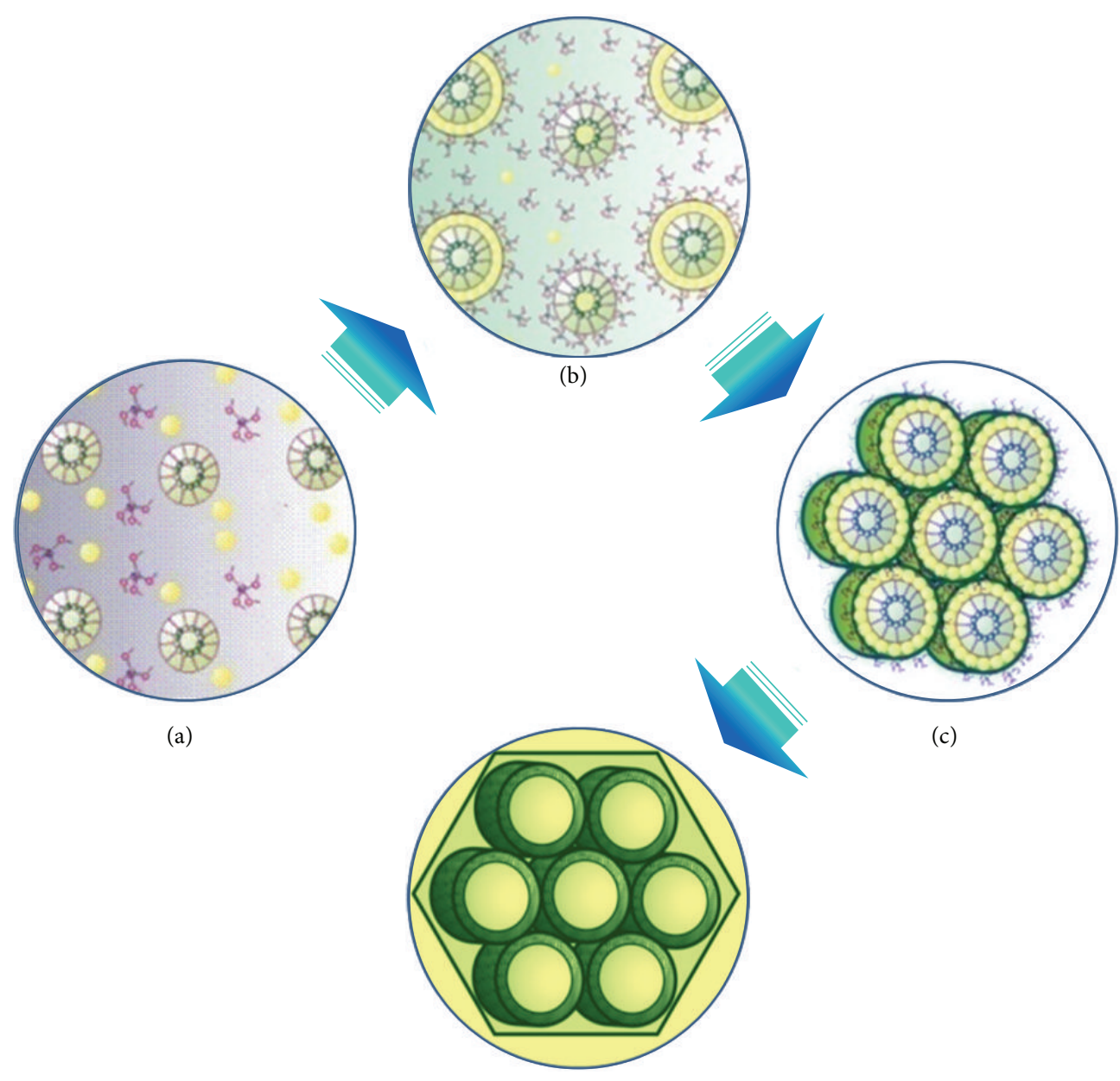

(d)

FIGURE 2: Schematic diagram of the soft-template synthesis of ordered mesoporous metal oxides; (a) starting precursors, (b) self-assembly of surfactant and metal precursors, (c) hybrid of metal oxides and polymers, and (d) ordered mesoporous metal oxides.

of nanomaterials (nanotubes and nanowires) by using anodic alumina membrane as templates [39]. Since the success fabrication of ordered mesoporous silica, the hard-template method has been developed for the synthesis of crystalline ordered mesoporous metal oxides [40-44]. Figure 4 shows a diagram for the hard-template synthesis of ordered mesoporous metal oxides. Typically, the hard-template synthesis includes the (i) fabrication of mesoporous structure materials (silica or carbon) as hard-templates by the conventional softtemplate direct-synthesis using copolymer surfactants, the (ii) filling of metal oxide precursors into the nanopores of hard-templates, the (iii) calcination that converts the metal precursors to metal oxides, and the (iv) selective etching of the hard-templates. In some cases, the filling and calcination processes (ii and iii) were repeated several times to ensure the sufficient filling of metal oxides into the nanopores of templates [43]. The common and popular hard-templates used for the synthesis of semiconducting metal oxides mesoporous are the highly ordered silica and carbon [35, 4348]. The fabrication method is the post synthesis, where the mesoporous template is fabricated first, and then the metal precursor is filled in the pores to generate the desired oxide.
This synthesis is sometimes called nanocasting [35, 45-47] or replication method [48].

Hard-template method has been applied effectively to the synthesis of various mesoporous semiconducting metal oxides such as $\mathrm{ZnO}$ [43], $\mathrm{Cr}_{2} \mathrm{O}_{3}$ [49], $\mathrm{CeO}_{2}$ [50], $\mathrm{Co}_{3} \mathrm{O}_{4}$ [4547], $\mathrm{MgO}[51], \mathrm{In}_{2} \mathrm{O}_{3}[52,53], \mathrm{Fe}_{3} \mathrm{O}_{4}$ [54], and $\mathrm{WO}_{3-x}$ [55]. Schüth et al. $[56,57]$ reported on the hard-template synthesis of nanostructured porous $\mathrm{Co}_{3} \mathrm{O}_{4}$ using two-dimensional (2D) hexagonal SBA-15 and three-dimensional (3D) cubic KIT-6 silica as templates. We also used mesoporous silica monoliths as a hard-template for the synthesis of crystalline tungsten oxide, and the data are reported in Figure 5. Highly ordered mesoporous silica monoliths were synthesized by an instant direct-templating method. Figure 5 shows the TEM images of mesoporous silica template and tungsten oxide obtained by hard-template. The synthesis involved the dispersion of mesoporous silica templates in ethanol solution of tungsten hexachloride, with stirring for $1 \mathrm{~h}$ at room temperature, followed by evaporation of the ethanol, and calcination at high temperature. These processes were repeated twice to enhance the loading amount of tungsten precursors. The silica template was removed by leaching with sodium hydroxide 


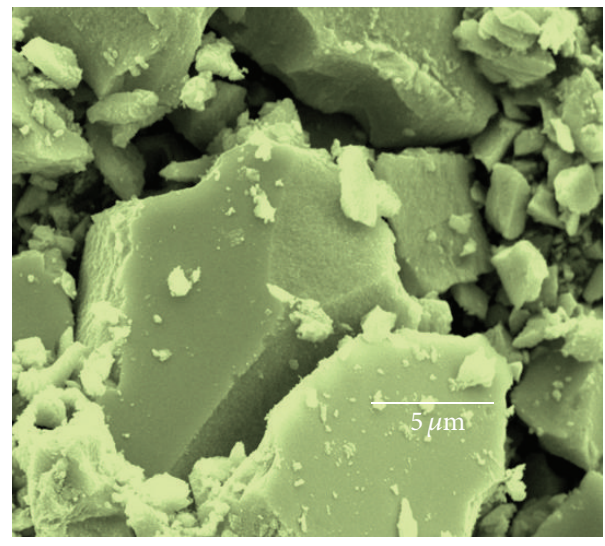

(a)

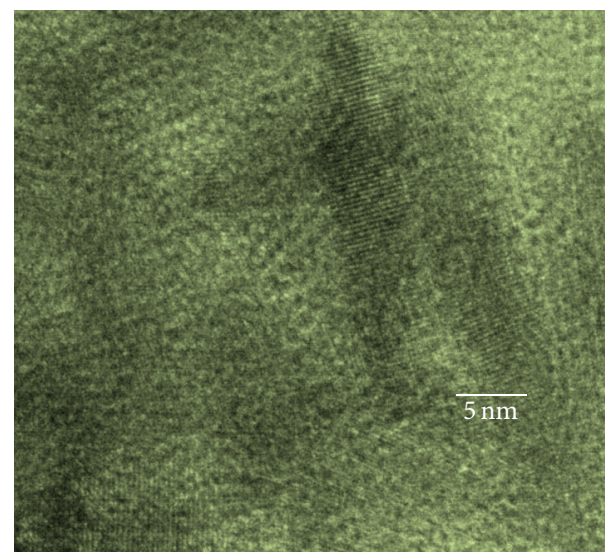

(c)

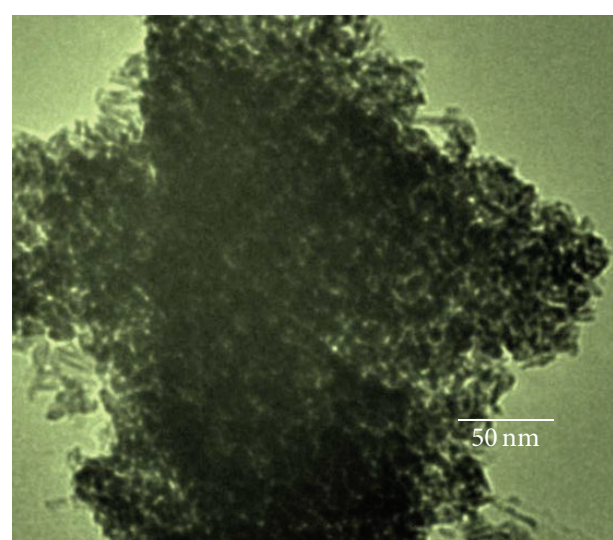

(b)

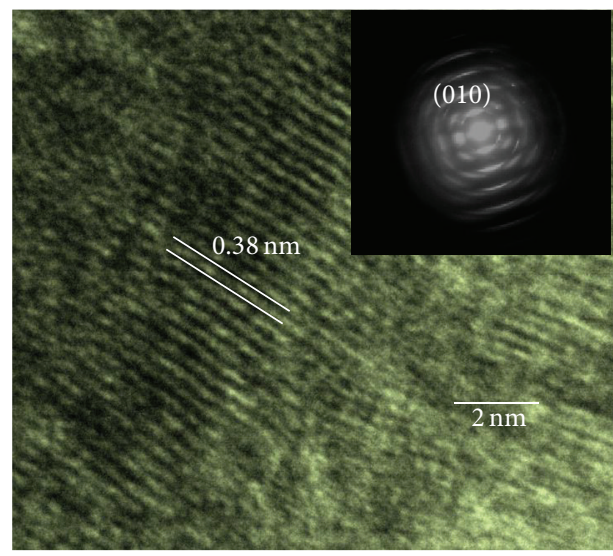

(d)

FIGURE 3: (a) SEM, (b) TEM, and (c, d) HRTEM images of mesoporous $\mathrm{WO}_{3}$ synthesized by soft-template method.

aqueous solution. The obtained mesoporous $\mathrm{WO}_{3}$ samples have specific surface area of $70-153 \mathrm{~m}^{2} / \mathrm{g}$ and pore sizes of 3-7 nm. As demonstrated, the hard-template method is effective for the synthesis of crystalline ordered mesoporous metal oxides. However, hard-template synthesis is both costly and time-consuming because the synthesis requires long preparation and multiple processes, including the fabrication of porous templates, the incubation of metal precursors in the nanopores of templates, conversion of metal precursors into metal oxides, and selectively etching the templates $[35,43-$ 57]. In addition, the method has some drawbacks, which include the difficulty in loading the amount of metal oxides into the pore channels of mesoporous silica because of possible blockage by the metal oxides at the mouths of the pore channels during the incubation and/or filling into the pore channels of mesoporous silica, which prevents the further filling process. In turn, the covering of the pore channels led to the coating of metal oxides on the outside surface of the templates particles as the bulk dense samples, but not on the mesoporous structures. Furthermore, the hard-template method also faces challenges in the selective etching of the templates, specifically when the desired synthesis materials can interact with the templates to form other phases; in addition, oxide phase and/or the desired synthesis materials can easily be dissolved in etching solution.
2.3. Template-Free Synthesis of Meso-/Nanoporous Metal Oxides. Synthesis of porous metal oxides without using templates has gained interests in recent years. Several methods such as sol-gel process [58], hydrothermal hot-press [59], anodic anodization [60], and electrodeposition [61] have also been developed for the synthesis of porous metal oxides. The anodic anodization method enables the synthesis of highly ordered mesoporous metal oxides, such as $\mathrm{Al}_{2} \mathrm{O}_{3}$ and $\mathrm{TiO}_{2}$, but the products are usually of amorphous phases. In addition, the ordered $\mathrm{Al}_{2} \mathrm{O}_{3}$ fabricated by anodic anodization method is not suitable for the resistive gas sensor application because of its insulating behaviors. The template-free methods exhibited advantages by being simple, inexpensive, and scalable technique for the synthesis of meso-/nanoporous metal oxides [62]. Figure 6 shows a diagram process for the template-free synthesis of meso-/nanoporous metal. The synthesis generally involves the fabrication of intermediate phase of metal oxides, such as metal hydroxide, or metal carbonate and the conversion of intermediate phases into meso-/nanoporous metal oxides [63]. In our recent work, we introduced the synthesis of mesoporous $\mathrm{NiO}$ nanosheets by template-free method [64]. This material showed good sensing characteristics to highly toxic $\mathrm{NO}_{2}$ gas and potentially for large scale fabrication of sensors. 


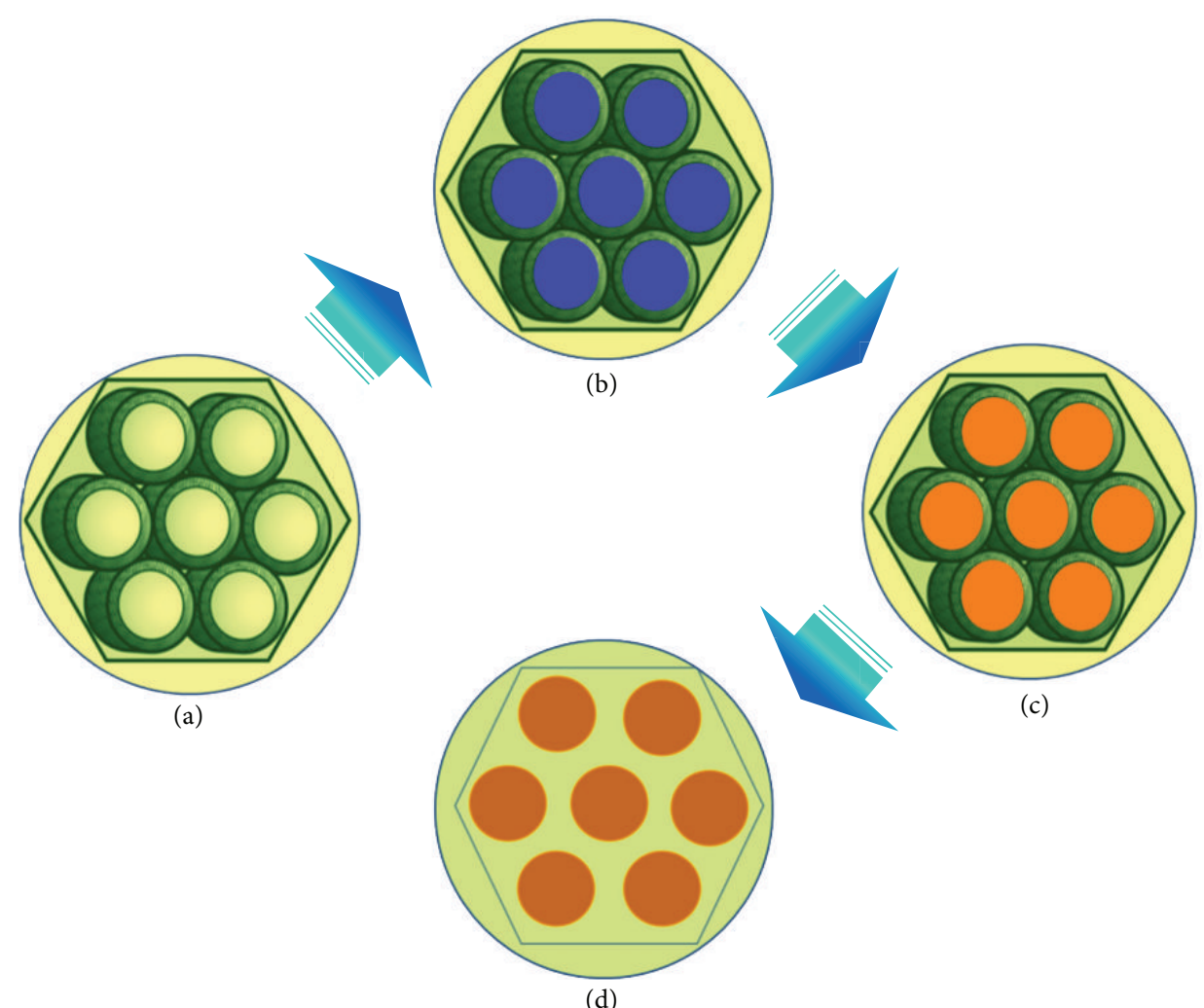

FIGURE 4: Schematic diagram of the hard-template synthesis of ordered mesoporous metal oxides.

Different meso-/nanoporous metal oxides were synthesized successfully by using template-free method. Figure 7 shows the SEM and TEM images of mesoporous $\mathrm{NiO}$ nanosheets synthesized by template-free hydrothermal method. First, the hexagonal $\mathrm{Ni}(\mathrm{OH})_{2}$ nanosheets were prepared by hydrothermal method without using any surfactant or structure-directing agent. Thereafter, the $\mathrm{Ni}(\mathrm{OH})_{2}$ was converted into mesoporous $\mathrm{NiO}$ nanosheets by thermal oxidation [64]. The mesoporous $\mathrm{NiO}$ nanosheets are highly crystalline with tunable pore size just by simply varying the synthesis conditions. The hydrothermal method could also fabricate other mesoporous metal oxides such as $\operatorname{In}_{2} \mathrm{O}_{3}[65]$, $\mathrm{Fe}_{2} \mathrm{O}_{3}$ [66], and $\mathrm{Co}_{3} \mathrm{O}_{4}[63,67]$. The mesoporous metal oxides are of excellent materials for application in gas sensing fields $[68-74]$.

2.4. Meso-/Nanoporous Composite of Semiconducting Metal Oxide and Silica. The use of mesoporous metal oxide composites for gas sensor applications has gained interest because of its enhanced sensitivity and selectivity [75]. The most popular mesoporous metal oxide composites used for gas sensors application are based on mesoporous silica because of the easy synthesis and control of the mesoporous structures. In addition, the incorporation of metal oxide in the mesoporous silica leads to an increase in the sensitivity and selectivity of materials $[75,76]$. Recently, we reported on the directsynthesis of high ordered silica and metal oxide nanocomposites (HOM/MO) for gas sensor application. The synthesis involved an instant, one-pot, and direct-template method using Brij $56\left(\mathrm{C}_{16} \mathrm{EO}_{10}\right)$ surfactant as soft-template. In typical synthesis, $0.815 \mathrm{~g}$ Brij 56 was dissolved in $1.63 \mathrm{~g}(\sim 0.013 \mathrm{~mol})$ tetramethoxysilane (TMOS) in a round balloon flask $(300 \mathrm{~mL}$ in volume) and agitated at $60^{\circ} \mathrm{C}$ in a water bath for $1 \mathrm{~min}$ to obtain a well-homogenized mixture. Subsequently, the predissolved metal chloride $\left(\mathrm{SnCl}_{2} \cdot 2 \mathrm{H}_{2} \mathrm{O}, \mathrm{ZnCl}_{2}, \mathrm{NiCl}_{2}\right.$, $\mathrm{CuCl}_{2} \cdot 2 \mathrm{H}_{2} \mathrm{O}$, or $\mathrm{FeCl}_{2} \cdot 4 \mathrm{H}_{2} \mathrm{O}$ ) in $0.815 \mathrm{~g}$ acidified aqueous solution $\mathrm{HCl} / \mathrm{H}_{2} \mathrm{O}(\mathrm{pH}$ 1.3) was added to the mixture. The exothermic hydrolysis and condensation of TMOS occurred rapidly. The samples were dried under vacuum using a rotary evaporator to obtain a gel-like material at $45^{\circ} \mathrm{C}$ for $\sim 5 \mathrm{~min}$. The mass ratio of Brij56: TMOS: $\mathrm{HCl} / \mathrm{H}_{2} \mathrm{O}$ was $1: 2: 1$. The amount of adding metal chloride was calculated according to the atomic ratio of metal to silicon $(r=\mathrm{M} / \mathrm{Si})$, varying from 0.11 to 4.00 . The Brij56 soft-template was removed by calcination at $500^{\circ} \mathrm{C}$ for $8 \mathrm{~h}$ to obtain the $\mathrm{HOM} / \mathrm{MO}$ nanocomposite monoliths [77]. Figure 8(a) shows the SEM, STEM, and TEM images of the $\mathrm{HOM} / \mathrm{SnO}_{2}$ nanocomposites. Its particles are of nanometer to micrometer dimensions. The EDS results indicate the presence of $\mathrm{C}, \mathrm{O}, \mathrm{Sn}$, and Si (Figure 8(a), inset); however, there was no detectable signal of the $\mathrm{Cl}$ in the EDS spectra of MO/HOM. The presence of $\mathrm{C}$ was due to contamination, whereas $\mathrm{O}, \mathrm{Sn}$, and $\mathrm{Si}$ originated from the sample. The atomic composition was $1.0 \% \mathrm{C}, 66.0 \% \mathrm{O}, 13.1 \% \mathrm{Sn}$, and $19.9 \% \mathrm{Si}$, which is consistent with the calculation from the precursors $(r=$ $0.67)$. Figure $8(\mathrm{~b})$ shows a bright field STEM image of an $\mathrm{HOM} / \mathrm{SnO}_{2}$ nanocomposite monolith with a size of $\sim 350 \mathrm{~nm}$. The $\mathrm{SnO}_{2}$ nanocrystals (dark dots, $5 \mathrm{~nm}$ average size) were 


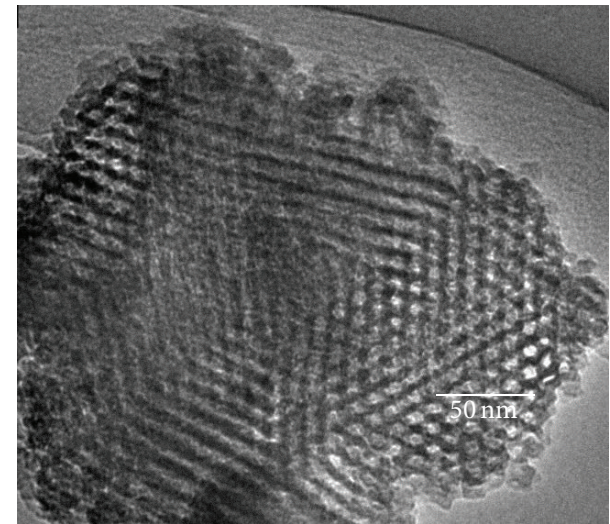

(a)

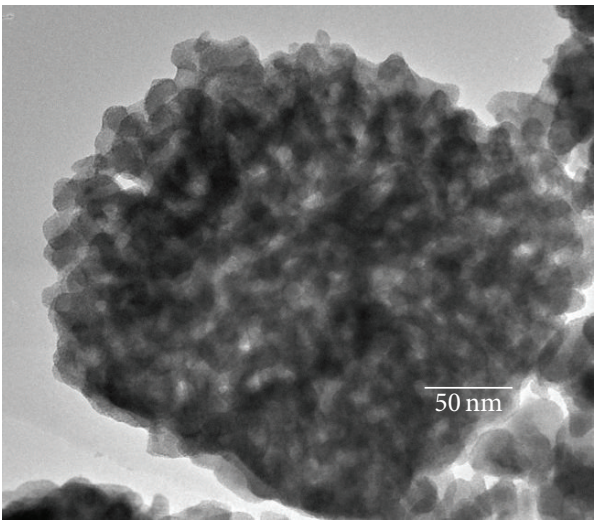

(c)

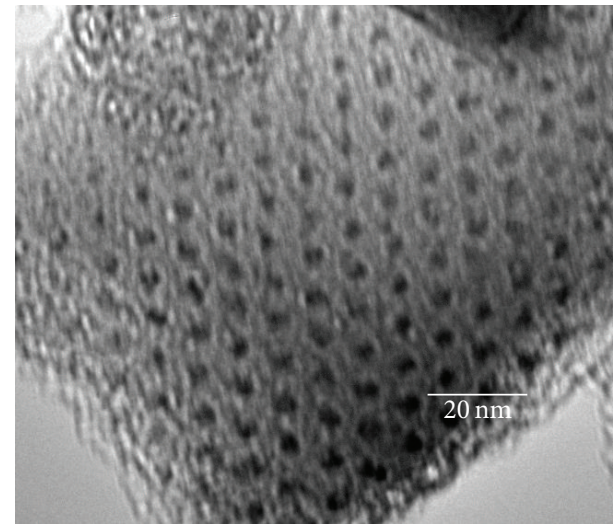

(b)

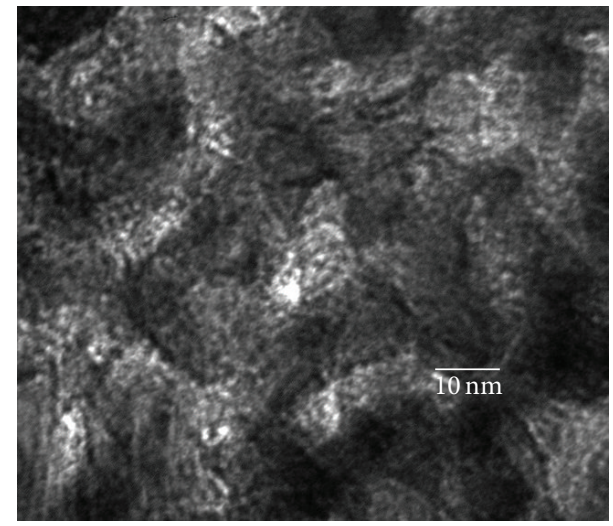

(d)

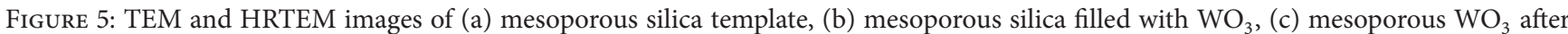
etching silica template selectively, and (d) HRTEM image $\mathrm{WO}_{3}$.

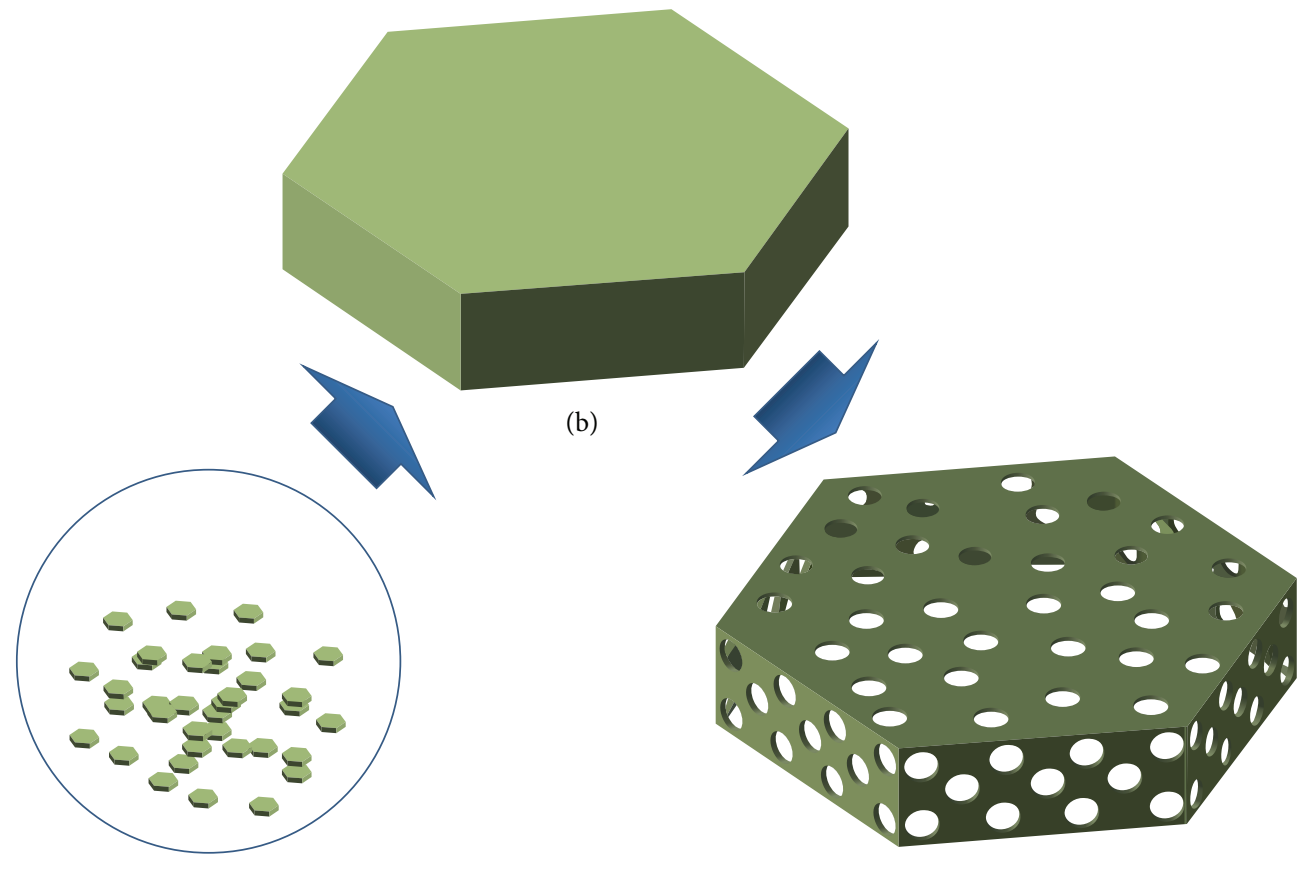

(a)

(c)

FIGURE 6: Schematic diagram of the template-free synthesis of meso-/nanoporous metal oxides. 


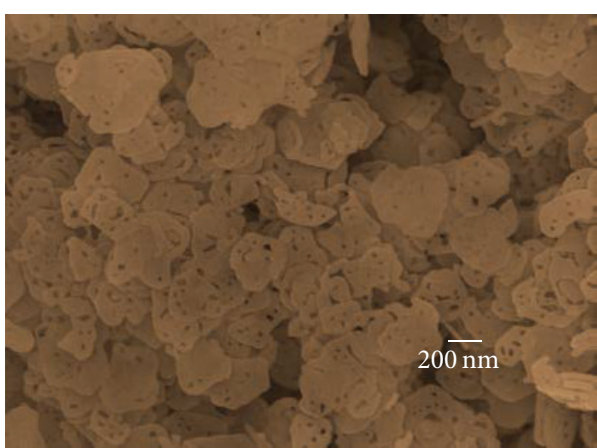

(a)

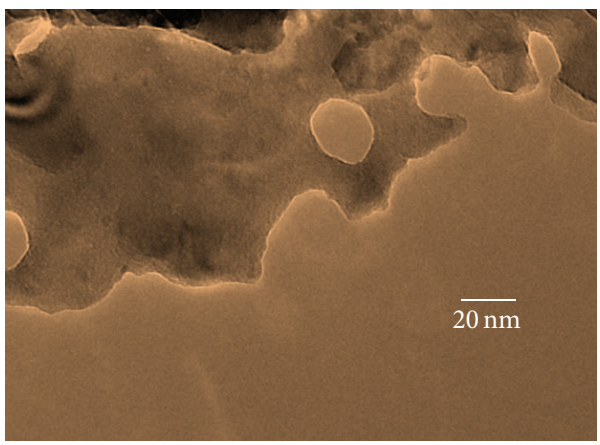

(c)

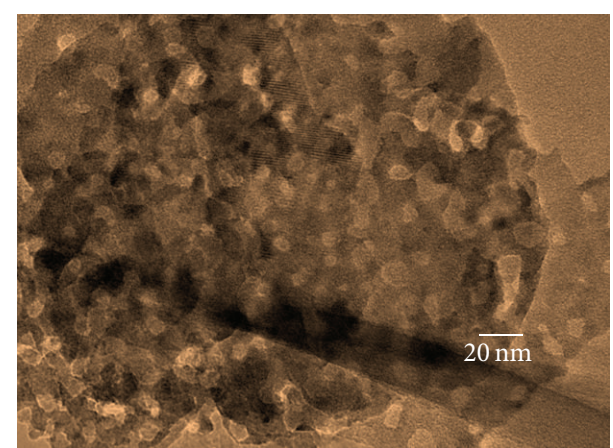

(b)

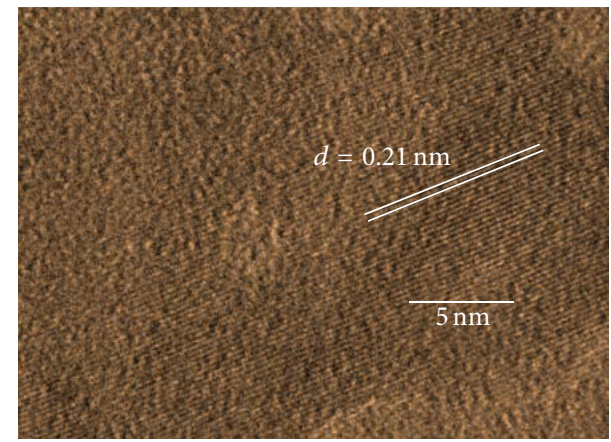

(d)

FIGURE 7: (a) SEM, (b, c) TEM, and (d) HRTEM images of crystalline mesoporous NiO nanosheets fabricated by a template-free hydrothermal method.
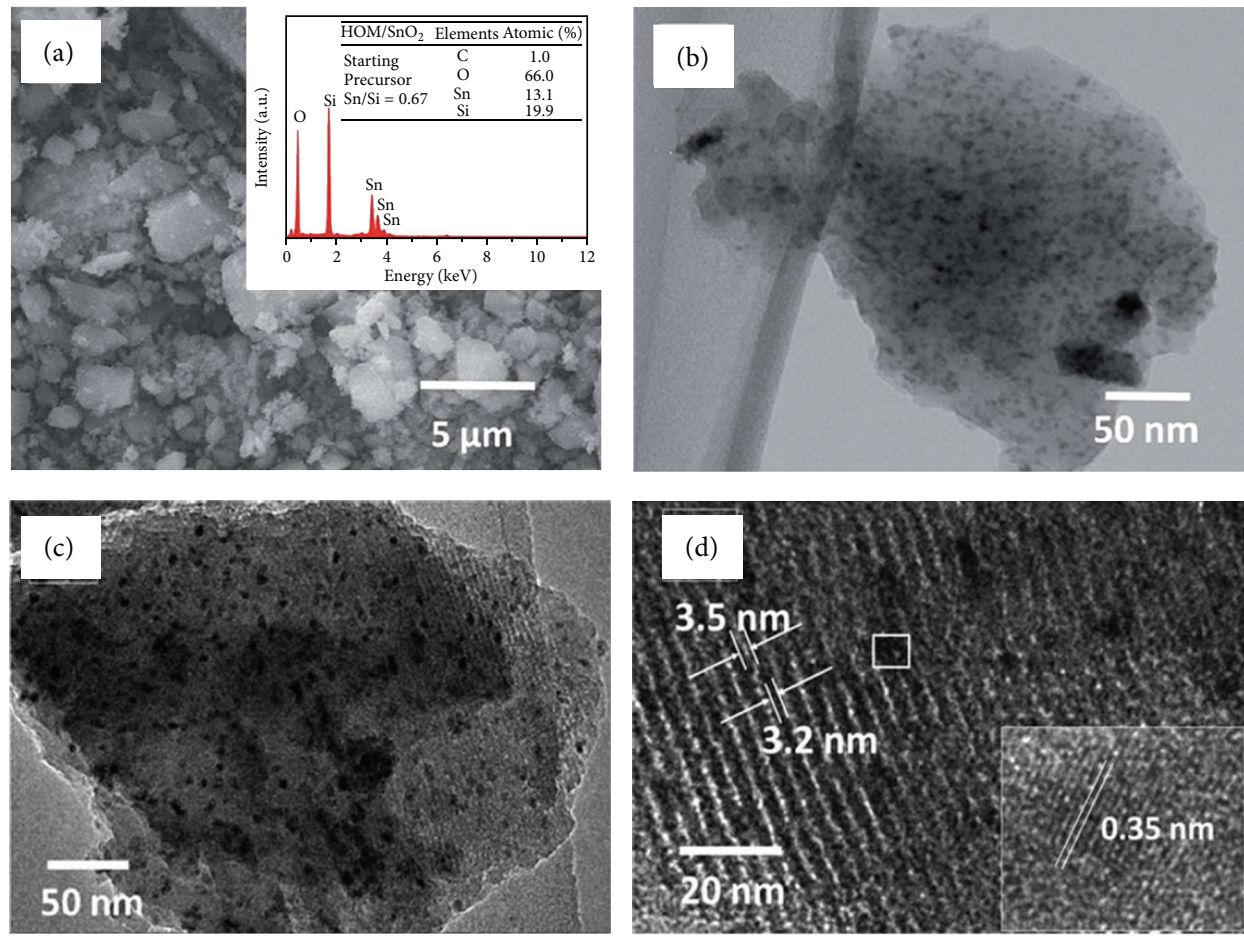

Figure 8: (a) SEM, (b) STEM, and (c, d) HRTEM images of the $\mathrm{HOM} / \mathrm{SnO}_{2}$ nanocomposites. 


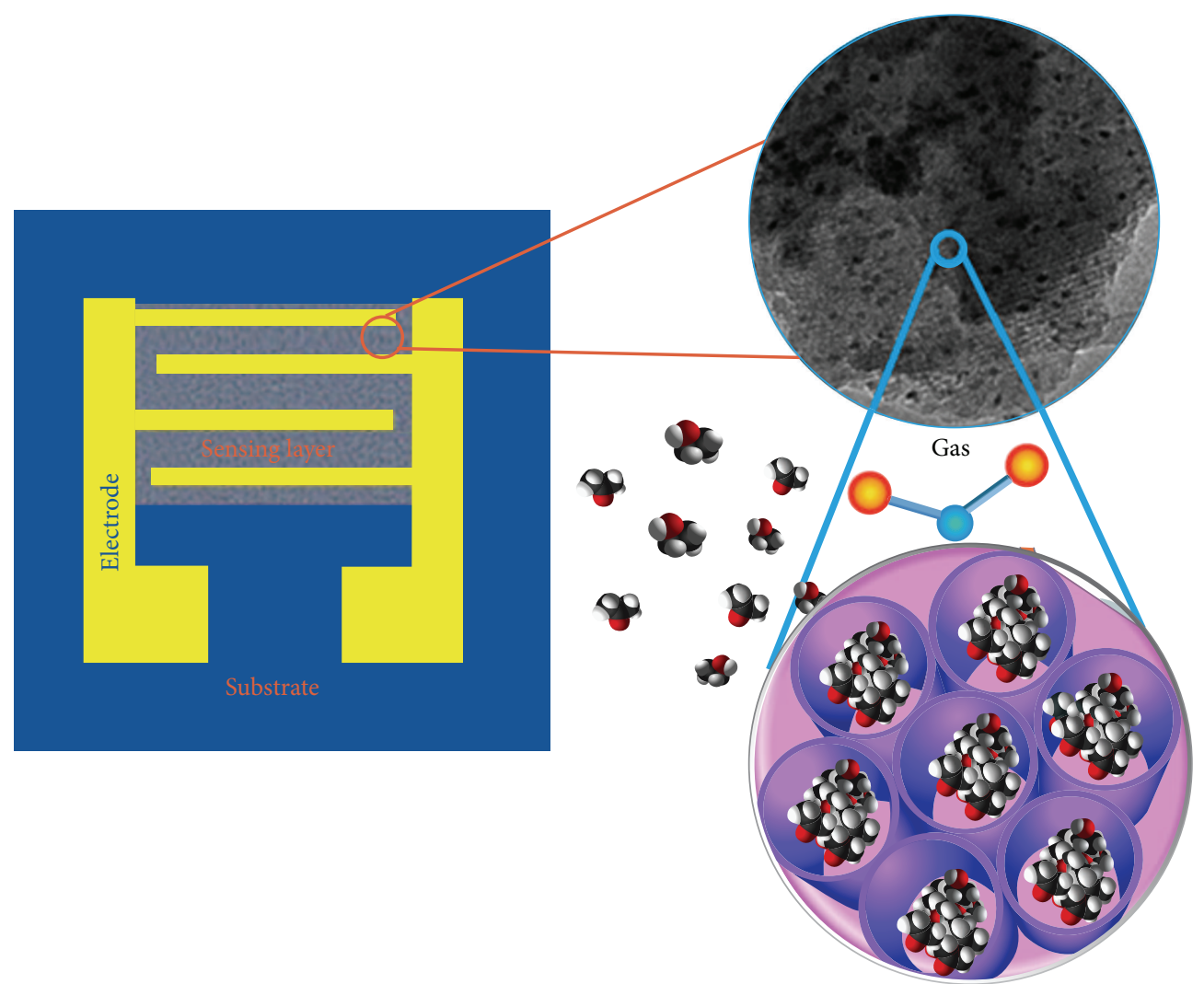

FigurE 9: A design of gas nanosensor based on meso-/nanoporous metal oxides, which utilizes the porous structure and large specific surface area materials to enhance the sensing sites and gas sensing performances.

distributed homogenously in the matrix of the mesoporous silica. No aggregation of $\mathrm{SnO}_{2}$ particles can be observed in the STEM image. The distribution of the nanocrystalline $\mathrm{SnO}_{2}$ in the matrix of mesoporous silica prevented the grain growth of nanocrystals and increased the long-term stability of sensors made from the nanocomposites. Figures 13(c) and 13(d) show the HRTEM images of the $\mathrm{HOM} / \mathrm{SnO}_{2}(r=$ $0.67)$ nanocomposites. Uniform cylindrical pore channels ran through the monolith (Figure $8(\mathrm{c})$ ), which confirmed its high-order structure. The wall thickness and the pore size averaged 3.5 and $3.2 \mathrm{~nm}$, respectively (Figure $8(\mathrm{~d})$ ). The HRTEM images also indicate the presence of $\mathrm{SnO}_{2}$ nanoparticles (dark dots), which had an average diameter of about $5 \mathrm{~nm}$ and were distributed homogenously in the matrix of the mesoporous silica (bright region). The higher-magnification HRTEM image (Figure 8(d), inset) of the dark dot confirmed that the $\mathrm{SnO}_{2}$ nanoparticle was a single crystal. The lattice fringes were clearly observed; the distance between each was found to be $0.33 \mathrm{~nm}$, which corresponded to the (110) interplanar spacing of tetragonal $\mathrm{SnO}_{2}$.

\section{Meso-/Nanoporous Metal Oxides for Gas Sensors}

3.1. Design of Meso-/Nanoporous Metal Oxide-Based Gas Sensors. To improve the gas sensor performances by enhancing the total exposure volume of sensing materials to analytical gases, we recently designed the gas nanosensors, as shown in Figure 9. The gas nanosensors involved the integrated electrodes deposited on a thermally oxidized silicon substrate. To this integrated substrate, the meso-/nanoporous metal oxides with different geometrical designs of monoliths, mesocages, hollow spheres, nanosheets, nanorods, and nanowires were sprayed or screen printing deposited to act as sensing layers. The meso-/nanoporous metal oxide sensing materials have numerous meso-/nanopores and large specific BET surface area, which enable the analytical gas molecules to be easily adsorbed on the total volume of the sensing layers, resulting in rapid response time and supervisor sensitivity [71]. The selectivity of gas nanosensors can be improved by selecting proper sensing metal oxides and/or using the nanocomposites of metal oxides.

Figure 10 shows the SEM images of meso-/nanoporous metal oxide-based gas nanosensors fabricated by a thick film technique [38]. This technique enables the controlled fabrication of inexpensive and scalable gas nanosensors, whereas up to hundreds of gas sensing devices can be fabricated on a 4 -inch silicon wafer. The interdigitated $\mathrm{Pt} / \mathrm{Ti}$ electrodes were deposited onto a thermally oxidized silicon substrate by a sputtering system, using a conventional lithography technique. The electrode contained 18 pairs of fingers, each $800 \mu \mathrm{m}$ long and $20 \mu \mathrm{m}$ wide, respectively. The meso-/nanoporous metal oxides were deposited between and/or over the electrode fingers and acted as conducting 


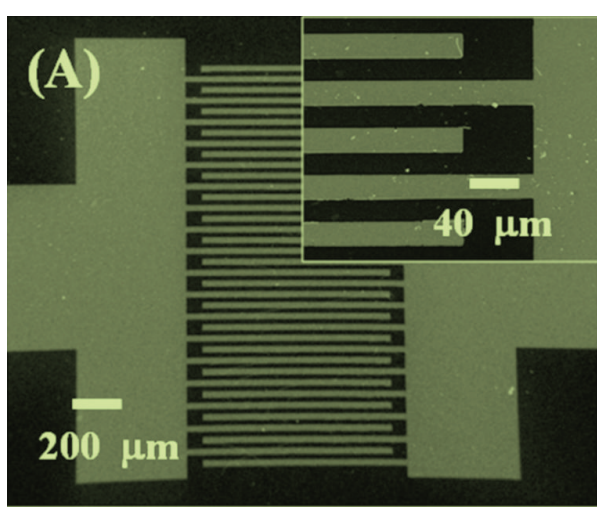

(a)

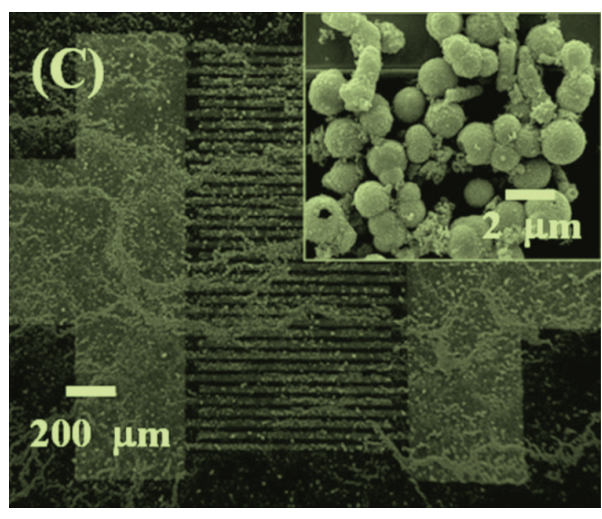

(c)

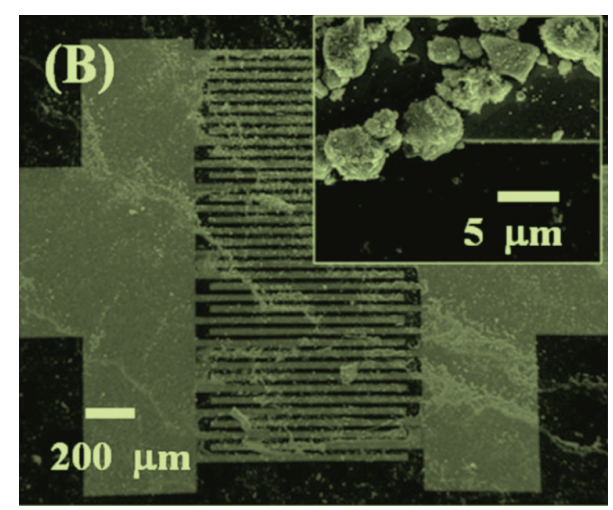

(b)

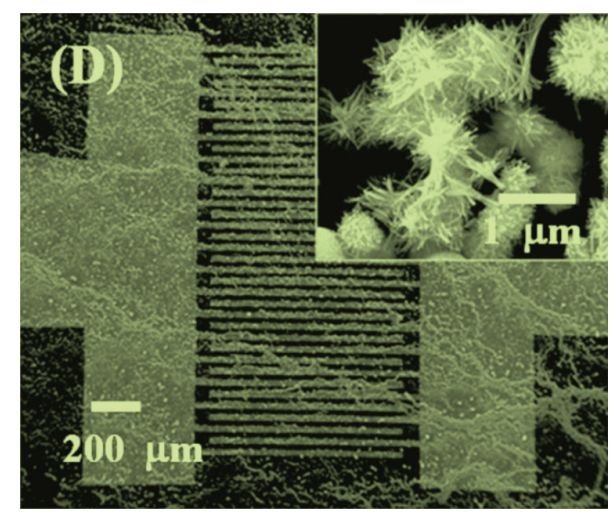

(d)

FIGURE 10: SEM images of the meso-/nanoporous metal oxides based gas nanosensors: (a) bare electrodes, (b) mesoporous $\mathrm{WO}_{3}$, (c) hollow sphere $\mathrm{WO}_{3}$, and (d) flower $\mathrm{WO}_{3}$.

and sensing layers for gas adsorption. Using this synthetic technique, ordered and disordered meso-/nanoporous metal oxides can be deposited, and no distortion of material structures occurred during processing, as revealed by the SEM images (inset, Figure 10). Details about the gas sensing characteristics of the devices were reported in [38].

\subsection{Sensitivity of Meso-/Nanoporous Metal Oxide-Based Gas} Sensors. Sensitivity is one of the most important parameters of the sensors in practical applications. Higher sensitivity makes the sensor better because it allows the detection of the lower concentration of analytic gas. We have used different meso-/nanoporous metal oxides for gas sensing applications. The meso-/nanoporous p-type $\mathrm{Co}_{3} \mathrm{O}_{4}$ nanorods were used for highly sensitive VOC gas sensor applications [67]. Different meso-/nanoporous metal oxide semiconductors can be used for different sensors. Figure 11 presents the response of the meso-/nanoporous $\mathrm{WO}_{3}$ to $\mathrm{NO}_{2}$; in the inset is the TEM image of the meso-/nanoporous $\mathrm{WO}_{3}$. The sensor's response to $1,2.5$, and $5 \mathrm{ppm}$ concentrations of $\mathrm{NO}_{2}$ gas at $150^{\circ} \mathrm{C}$ was $850 \%, 6903 \%$, and $21155 \%$, respectively. The values decreased to $123 \%, 966 \%$, and $2893 \%$, and $3 \%, 38 \%$, and $136 \%$ at temperatures of 200 and $300^{\circ} \mathrm{C}$, respectively. Comparing the sensor response obtained in this work with the values of the porous $\mathrm{WO}_{3}$ nanorods, or the solvothermally synthesized $\mathrm{W}_{18} \mathrm{O}_{49}$ nanorods, the mesoporous tungsten oxide

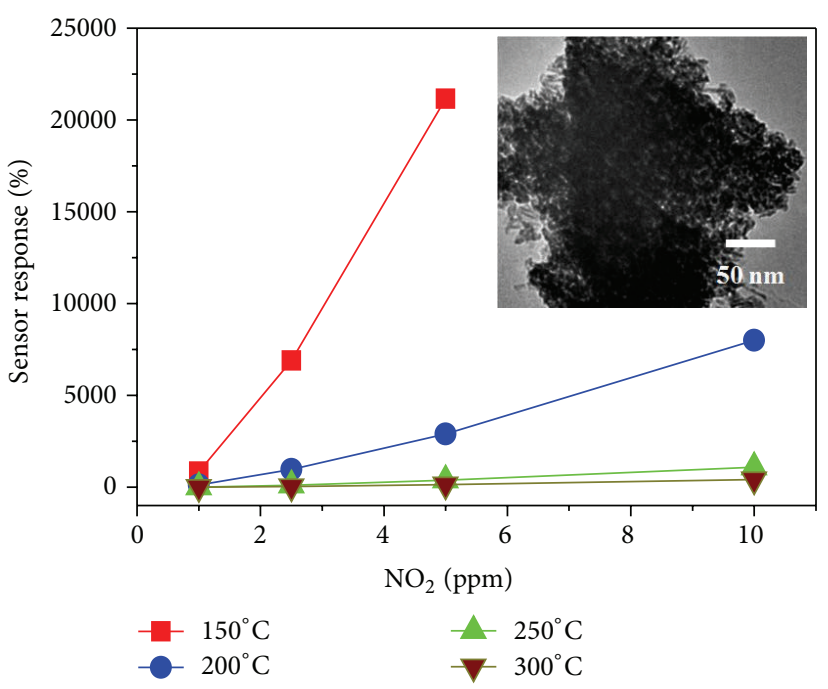

FIGURE 11: Sensitivity of the meso-/nanoporous tungsten oxide to $\mathrm{NO}_{2}$ measured at different temperatures.

nanoplates exhibited much higher sensitivity [38]. The high sensor response obtained in this study was possible because of the large specific surface area and the small crystalline size of materials; the larger surface area provides a larger 


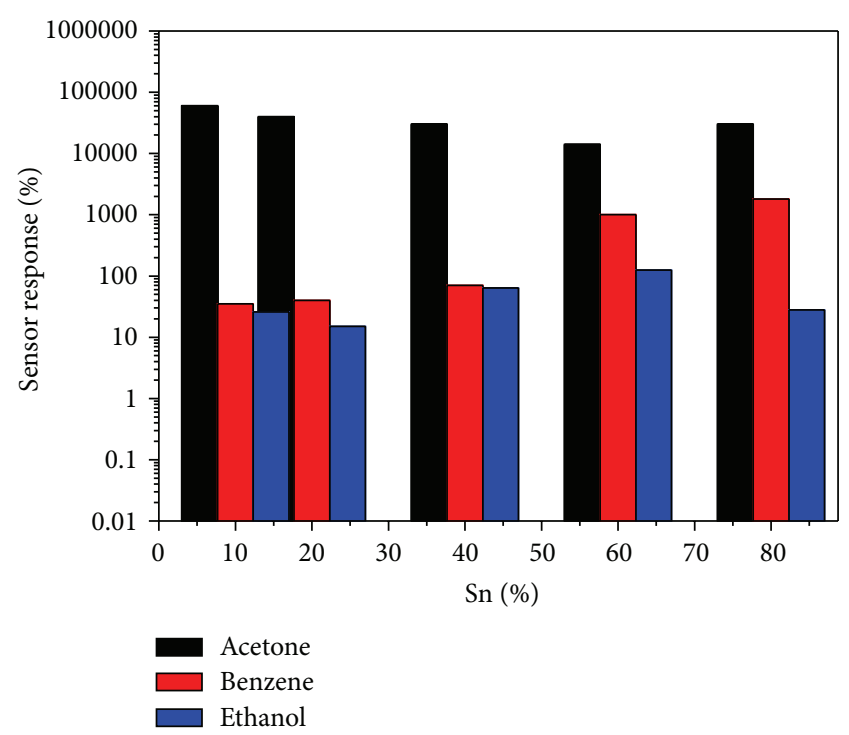

(a)

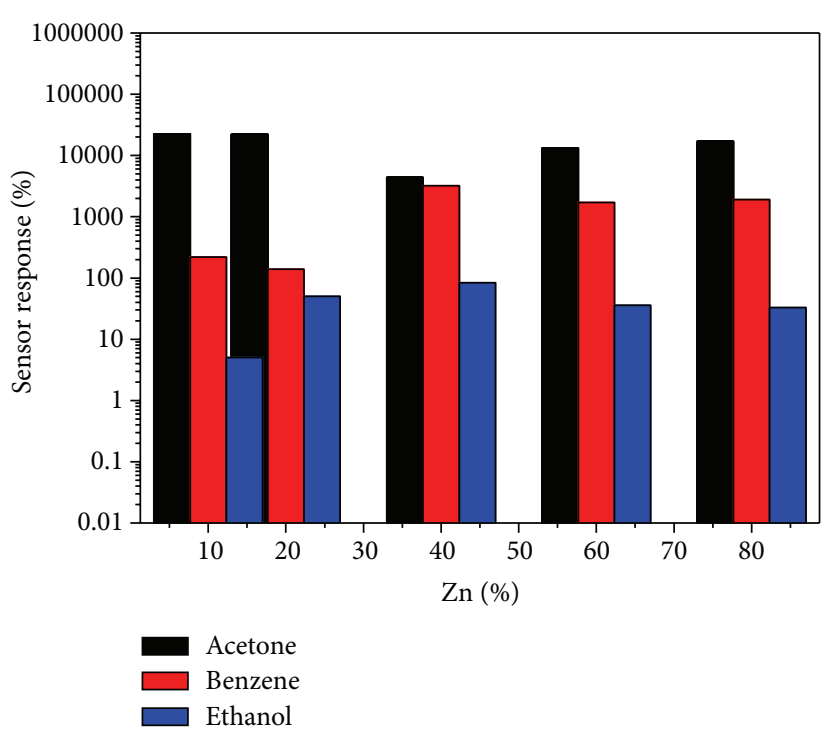

(b)

FIGURE 12: Selectivity of the HOM/MO nanocomposite nanosensors to VOCs: (a) effect of $\mathrm{SnO}_{2}$ and (b) $\mathrm{ZnO}$ concentration.

sensing site for $\mathrm{NO}_{2}$ adsorption, thus enhancing the sensor's response. The linear dependence on sensor's response as a function of acetone concentration in measured range is one of its advantages in practical application because of the easy design in the readout signal circuit.

\subsection{Selectivity of Meso-/Nanoporous Metal Oxide-Based Gas} Sensors. Selectivity is another most important parameter in the practical application of gas sensors. Generally, the selectivity of metal oxide-based resistive gas sensors can be achieved by using some additive metals. Figure 12(a) shows the effects of the doping level in the $\mathrm{HOM} / \mathrm{SnO}_{2}$ nanocomposites on their VOC sensing. The sensor's response to benzene increased from $55 \%$ to $1,050 \%$ when the Sn doping content increased from $10 \%(r=0.11)$ to $80 \%(r=4)$, whereas the response to ethanol appeared to be independent of the Sn content. Sensor's response to acetone decreased with higher Sn content within 10\% to $60 \%$ but further increased at $80 \% \mathrm{Sn}$ [77]. The effect of $\mathrm{Zn}$ doping on the response of the $\mathrm{HOM} / \mathrm{ZnO}$ monolith sensors is presented in Figure 12(b). The sensors still showed the highest response to acetone. However, the sample doped with $40 \% \mathrm{Zn}(r=0.57)$ showed the lowest response to acetone, although it exhibited the highest response to benzene and ethanol compared with the other samples. From the experimental data, the enhancement of the sensor's sensitivity to benzene is suggested; the use of high doping level of $\mathrm{Sn}$ or $\mathrm{Zn}$ is also preferred. However, in both cases, the sensors exhibited extreme selectivity for the detection of acetone, suggesting a method to improve the selectivity of the materials.

\subsection{Stability of Meso-/Nanoporous Metal Oxide-Based Gas} Sensors. In practical applications, good transient and longterm stability of the gas sensor is expected for the reusability of the devices. The stability of sensors is dependent on the thermal and chemical stability of the sensing materials upon gas sensing measurements. Generally, the gas sensors operate at high temperature of about $200-400^{\circ} \mathrm{C}$. At such high operating temperature, the stability of the metal oxidebased sensors tends to decrease as a result of the grain growth during measurement. In addition, the chemical interaction between analytic gas and sensing materials to form a new phase destroys the stability of the sensors [29, 30]. The amorphous or polycrystalline metal oxides have poor stability because they are not thermally stable as a result of the crystallization and grain growth of materials during sensor operation. The crystallization and grain growth of materials lead to a shift of base line resistance and also decrease the sensitivity and stability of device. Oppositely, the high crystallinity of materials such as a single crystal is very stable under sensor operation condition and results in a better stability [78]. By using meso-/nanoporous metal oxides with high crystallinity, a gas sensor with very high stability can be fabricated. Figure 13 shows the stability of the single crystal meso-/nanoporous $\mathrm{ZnO}$ nanorod sensor after several cycles of exposure to $\mathrm{NO}_{2}$ and back to dry air [79]. The sensor showed very good stability, a stable signal, a high response, and high recovery. Sensor's response did not decay after prolonged storage, even after eight cycles of switching on/off from dry air to gas and back to dry air. This is the result of the high crystallinity of the fabricated $\mathrm{ZnO}$, where the lattice fringes can be seen clearly in the HRTEM image (inset of Figure 13) with an interplanar spacing of $0.52 \mathrm{~nm}$. The HRTEM image also indicates that the $\mathrm{ZnO}$ nanorod is single crystalline and free of defects, with preferred growth direction along the $c$-axis of the hexagonal $\mathrm{ZnO}$ (JCPDS, 361451) [80]. The high crystallinity of the synthesized meso/nanoporous metal oxides prevented the grain growth during sensor operation at high temperature and enhanced the longterm stability of the sensors [78]. 


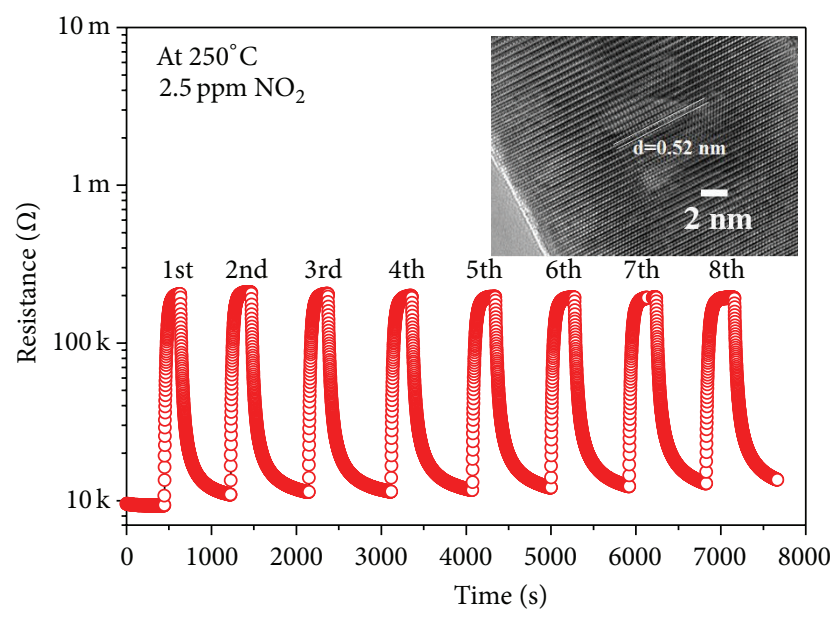

Figure 13: Transient stability of the sensor based on single crystal meso-/nanoporous $\mathrm{ZnO}$ nanorod upon eight-cycle exposure to $\mathrm{NO}_{2}$.

\section{Conclusions and Outlook}

We have briefly reviewed the recent research on the synthesis of mesoporous metal oxides for gas sensor applications. The general synthesis methods of soft-template, hard-template, and, specifically, template-free have been introduced for fabrication of meso-/nanoporous semiconducting metal oxides and their nanocomposites. The advantages and disadvantages of each synthesis method have been figured out. The mesoporous structures play important roles in the application of semiconducting metal oxides as gas sensors, in which the large specific surface areas with the ability to control the grain size, pore size, and pore architecture are of advantage for the enhancement of gas sensor performances. Specifically, the synthesis of nanomaterials, such as nanoparticles, nanorods, and nanowires contents of meso-/nanoporous structures, would be a great advantage for fabrication of advanced gas nanosensors for different applications. Furthermore, integration of low power consumption gas sensors into smart phones for human heath diagnostic is a perspective. The meso/nanoporous metal oxides are advantageous to the limited application to resistive type gas sensors, but also for optical sensors, electrochemical sensors, and calorimetric sensors.

\section{Conflict of Interests}

The authors declare that there is no conflict of interests regarding the publication of this paper.

\section{Acknowledgment}

This research was funded by the Vietnam National Foundation for Science and Technology Development (Nafosted, 103.02-2014.06).

\section{References}

[1] T. Seiyama, A. Kato, K. Fujiishi, and M. Nagatani, "A new detector for gaseous components using semiconductive thin films," Analytical Chemistry, vol. 34, no. 11, pp. 1502-1503, 1962.

[2] N. Taguchi, "A metal oxide gas sensor," Japanese Patent 4538200, 1962.

[3] N. D. Hoa, S. Y. An, N. Q. Dung, N. V. Quy, and D. J. Kim, "Synthesis of p-type semiconducting cupric oxide thin films and their application to hydrogen detection," Sensors and Actuators B: Chemical, vol. 146, no. 1, pp. 239-244, 2010.

[4] P. van Tong, N. D. Hoa, N. van Duy, and N. van Hieu, "Microwheels composed of self-assembled tungsten oxide nanorods for highly sensitive detection of low level toxic chlorine gas," RSC Advances, vol. 5, no. 32, pp. 25204-25207, 2015.

[5] N. D. Hoa, N. Van Quy, M. An et al., "Tin-oxide nanotubes for gas sensor application fabricated using SWNTs as a template," Journal of Nanoscience and Nanotechnology, vol. 8, no. 10, pp. 5586-5589, 2008.

[6] P. V. Tong, N. D. Hoa, N. V. Duy, V. V. Quang, N. T. Lam, and N. V. Hieu, "In-situ decoration of Pd nanocrystals on crystalline mesoporous $\mathrm{NiO}$ nanosheets for effective hydrogen gas sensors," International Journal of Hydrogen Energy, vol. 38, no. 27, pp. 12090-12100, 2013.

[7] N. Du, H. Zhang, B. Chen et al., "Porous indium oxide nanotubes: layer-by-layer assembly on carbon-nanotube templates and application for room-temperature $\mathrm{NH}_{3}$ gas sensors," Advanced Materials, vol. 19, no. 12, pp. 1641-1645, 2007.

[8] D.-J. Yang, I. Kamienchick, D. Y. Youn, A. Rothschild, and I.-D. Kim, "Ultrasensitive and highly selective gas sensors based on electrospun $\mathrm{SnO}_{2}$ nanofibers modified by Pd loading," Advanced Functional Materials, vol. 20, no. 24, pp. 4258-4264, 2010.

[9] J. H. Lee, "Gas sensors using hierarchical and hollow oxide nanostructures: overview," Sensors and Actuators B: Chemical, vol. 140, no. 1, pp. 319-336, 2009.

[10] S. J. Hwang, K. I. Choi, J. W. Yoon, Y. C. Kang, and J. H. Lee, "Pure and palladium-loaded $\mathrm{Co}_{3} \mathrm{O}_{4}$ hollow hierarchical nanostructures with giant and ultraselective chemiresistivity to xylene and toluene," Chemistry: A European Journal, vol. 21, no. 15, pp. 5872-5878, 2015.

[11] L. F. Zhu, J. C. She, J. Y. Luo, S. Z. Deng, J. Chen, and N. S. Xu, "Study of physical and chemical processes of $\mathrm{H}_{2}$ sensing of ptcoated $\mathrm{WO}_{3}$ nanowire films," Journal of Physical Chemistry C, vol. 114, no. 36, pp. 15504-15509, 2010.

[12] T. Kida, A. Nishiyama, Z. Hua, K. Suematsu, M. Yuasa, and $\mathrm{K}$. Shimanoe, " $\mathrm{WO}_{3}$ nanolamella gas sensor: porosity control using $\mathrm{SnO}_{2}$ nanoparticles for enhanced $\mathrm{NO}_{2}$ sensing," Langmuir, vol. 30, no. 9, pp. 2571-2579, 2014.

[13] L. Qin, J. Xu, X. Dong et al., "The template-free synthesis of square-shaped $\mathrm{SnO}_{2}$ nanowires: the temperature effect and acetone gas sensors," Nanotechnology, vol. 19, no. 18, Article ID 185705, 2008.

[14] S. V. N. T. Kuchibhatla, A. S. Karakoti, D. Bera, and S. Seal, "One dimensional nanostructured materials," Progress in Materials Science, vol. 52, no. 5, pp. 699-913, 2007.

[15] D. R. Patil and L. A. Patil, " $\mathrm{Cr}_{2} \mathrm{O}_{3}$-modified $\mathrm{ZnO}$ thick film resistors as LPG sensors," Talanta, vol. 77, no. 4, pp. 1409-1414, 2009.

[16] A. Umar, M. M. Rahman, and Y.-B. Hahn, "Ultra-sensitive hydrazine chemical sensor based on high-aspect-ratio $\mathrm{ZnO}$ nanowires," Talanta, vol. 77, no. 4, pp. 1376-1380, 2009. 
[17] D. Chen, X. Hou, H. Wen et al., "The enhanced alcohol-sensing response of ultrathin $\mathrm{WO}_{3}$ nanoplates," Nanotechnology, vol. 21, no. 3, Article ID 035501, 2010.

[18] X. Wang, N. Miura, and N. Yamazoe, "Study of $\mathrm{WO}_{3}$-based sensing materials for $\mathrm{NH}_{3}$ and $\mathrm{NO}$ detection," Sensors and Actuators B, vol. 66, no. 1, pp. 74-76, 2000.

[19] M. Hübner, C. E. Simion, A. Haensch, N. Barsan, and U. Weimar, "CO sensing mechanism with $\mathrm{WO}_{3}$ based gas sensors," Sensors and Actuators, B: Chemical, vol. 151, no. 1, pp. 103-106, 2010.

[20] W.-H. Tao and C.-H. Tsai, " $\mathrm{H}_{2} \mathrm{~S}$ sensing properties of noble metal doped $\mathrm{WO}_{3}$ thin film sensor fabricated by micromachining," Sensors and Actuators B: Chemical, vol. 81, no. 2-3, pp. 237247, 2002.

[21] S. R. Aliwell, J. F. Halsall, K. F. E. Pratt et al., "Ozone sensors based on $\mathrm{WO}_{3}$ : a model for sensor drift and a measured correction method," Measurement Science and Technology, vol. 12, no. 6, pp. 684-690, 2001.

[22] N. D. Hoa, N. V. Duy, and N. V. Hieu, "Crystalline mesoporous tungsten oxide nanoplate monoliths synthesized by directed soft template method for highly sensitive $\mathrm{NO}_{2}$ gas sensor applications," Materials Research Bulletin, vol. 48, no. 2, pp. 440448, 2013.

[23] H. Wang, Y. Qu, H. Chen, Z. Lin, and K. Dai, "Highly selective n-butanol gas sensor based on mesoporous $\mathrm{SnO}_{2}$ prepared with hydrothermal treatment," Sensors and Actuators, B: Chemical, vol. 201, pp. 153-159, 2014.

[24] X. Wang, S. Qiu, J. Liu, C. He, G. Lu, and W. Liu, "Synthesis of mesoporous $\mathrm{SnO}_{2}$ spheres and application in gas sensors," European Journal of Inorganic Chemistry, vol. 2014, no. 5, pp. 863-869, 2014.

[25] Y. Wang, P. Gao, D. Bao et al., "One pot, two phases: individual orthorhombic and face-centered cubic $\mathrm{ZnSnO}_{3}$ obtained synchronously in one solution," Inorganic Chemistry, vol. 53, no. 23, pp. 12289-12296, 2014.

[26] D. Bao, P. Gao, L. Wang et al., " $\mathrm{ZnO}$ nanorod arrays and hollow spheres through a facile room-temperature solution route and their enhanced ethanol gas-sensing properties," ChemPlusChem, vol. 78, no. 10, pp. 1266-1272, 2013.

[27] P. Gao, Y. Chen, Y. Wang, Q. Zhang, X. Li, and M. Hu, "A simple recycling and reuse hydrothermal route to $\mathrm{ZnO}$ nanorod arrays, nanoribbon bundles, nanosheets, nanocubes and nanoparticles," Chemical Communications, no. 19, pp. 27622764, 2009.

[28] N. Yamazoe, G. Sakai, and K. Shimanoe, "Oxide semiconductor gas sensors," Catalysis Surveys from Asia, vol. 7, no. 1, pp. 63-75, 2003.

[29] N. D. Hoa, N. Van Quy, H. Jung, D. Kim, H. Kim, and S.-K. Hong, "Synthesis of porous $\mathrm{CuO}$ nanowires and its application to hydrogen detection," Sensors and Actuators B, vol. 146, no. 1, pp. 266-272, 2010.

[30] P. Van Tong, N. D. Hoa, D. D. Trung, N. D. Quang, and N. Van Hieu, "Tungsten oxide urchin-flowers and nanobundles: Effect of synthesis conditions and heat treatment on assembly and gassensing characteristics," Science of Advanced Materials, vol. 6, no. 6, pp. 1081-1090, 2014.

[31] L. G. Teoh, I. M. Hung, J. Shieh, W. H. Lai, and M. H. Hon, "High sensitivity semiconductor $\mathrm{NO}_{2}$ gas sensor based on mesoporous $\mathrm{WO}_{3}$ thin film," Electrochemical and Solid-State Letters, vol. 6, no. 8, pp. G108-G111, 2003.
[32] J. Yang, K. Hidajat, and S. Kawi, "Synthesis of nano- $\mathrm{SnO}_{2} / \mathrm{SBA}$ 15 composite as a highly sensitive semiconductor oxide gas sensor," Materials Letters, vol. 62, no. 8-9, pp. 1441-1443, 2008.

[33] Y. Li, W. Luo, N. Qin et al., "Highly ordered mesoporous tungsten oxides with a large pore size and crystalline framework for $\mathrm{H}_{2} \mathrm{~S}$ sensing," Angewandte Chemie International Edition, vol. 53, no. 34, pp. 9035-9040, 2014.

[34] P. Yang, D. Zhao, D. I. Margolese, B. F. Chmelka, and G. D. Stucky, "Generalized syntheses of large-pore mesoporous metal oxides with semicrystalline frameworks," Nature, vol. 396, no. 6707, pp. 152-155, 1998.

[35] X. Sun, Y. Shi, P. Zhang et al., "Container effect in nanocasting synthesis of mesoporous metal oxides," Journal of the American Chemical Society, vol. 133, no. 37, pp. 14542-14545, 2011.

[36] W. Cheng, E. Baudrin, B. Dunn, and J. I. Zink, "Synthesis and electrochromic properties of mesoporous tungsten oxide," Journal of Materials Chemistry, vol. 11, no. 1, pp. 92-97, 2001.

[37] B. Sun, J. Horvat, H. S. Kim, W.-S. Kim, J. Ahn, and G. Wang, "Synthesis of mesoporous $\alpha-\mathrm{Fe}_{2} \mathrm{O}_{3}$ nanostructures for highly sensitive gas sensors and high capacity anode materials in lithium ion batteries," Journal of Physical Chemistry C, vol. 114, no. 44, pp. 18753-18761, 2010.

[38] N. D. Hoa and S. A. El-Safty, "Gas nanosensor design packages based on tungsten oxide: mesocages, hollow spheres, and nanowires," Nanotechnology, vol. 22, no. 48, Article ID 485503, 2011.

[39] C. R. Martin, "Nanomaterials: a membrane-based synthetic approach," Science, vol. 266, no. 5193, pp. 1961-1966, 1994.

[40] M. Tiemann, "Repeated templating," Chemistry of Materials, vol. 20, no. 3, pp. 961-971, 2008.

[41] Z. Zhang, F. Zuo, and P. Feng, "Hard template synthesis of crystalline mesoporous anatase $\mathrm{TiO}_{2}$ for photocatalytic hydrogen evolution," Journal of Materials Chemistry, vol. 20, no. 11, pp. 2206-2212, 2010.

[42] R. Ryoo, S. H. Joo, and S. Jun, "Synthesis of highly ordered carbon molecular sieves via template-mediated structural transformation," Journal of Physical Chemistry B, vol. 103, no. 37, pp. 7743-7746, 1999.

[43] T. Wagner, T. Waitz, J. Roggenbuck, M. Fröba, C.-D. Kohl, and M. Tiemann, “Ordered mesoporous $\mathrm{ZnO}$ for gas sensing," Thin Solid Films, vol. 515, no. 23, pp. 8360-8363, 2007.

[44] J. Roggenbuck, G. Koch, and M. Tiemann, "Synthesis of mesoporous magnesium oxide by CMK-3 carbon structure replication," Chemistry of Materials, vol. 18, no. 17, pp. 4151-4156, 2006.

[45] B. Z. Tian, X. Liu, L. A. Solovyov et al., "Facile synthesis and characterization of novel mesoporous and mesorelief oxides with gyroidal structures," Journal of the American Chemical Society, vol. 126, no. 3, pp. 865-875, 2004.

[46] Y. Wang, C.-M. Yang, W. Schmidt, B. Spliethoff, E. Bill, and F. Schüth, "Weakly ferromagnetic ordered mesoporous $\mathrm{Co}_{3} \mathrm{O}_{4}$ synthesized by nanocasting from vinyl-functionalized cubic Ia3d mesoporous silica," Advanced Materials, vol. 17, no. 1, pp. 53-56, 2005.

[47] W. Yue, A. H. Hill, A. Harrison, and W. Zhou, "Mesoporous single-crystal $\mathrm{Co} 3 \mathrm{O} 4$ templated by cage-containing mesoporous silica," Chemical Communications, no. 24, pp. 2518-2520, 2007.

[48] B. Tian, X. Liu, H. Yang et al., "General synthesis of ordered crystallized metal oxide nanoarrays replicated by microwavedigested mesoporous silica," Advanced Materials, vol. 15, no. 16, pp. 1370-1374, 2003. 
[49] K. Jiao, B. Zhang, B. Yue et al., "Growth of porous single-crystal $\mathrm{Cr}_{2} \mathrm{O}_{3}$ in a 3-D mesopore system," Chemical Communications, no. 45 , pp. 5618-5620, 2005.

[50] S. C. Laha and R. Ryoo, "Synthesis of thermally stable mesoporous cerium oxide with nanocrystalline frameworks using mesoporous silica templates," Chemical Communications, vol. 9, no. 17, pp. 2138-2139, 2003.

[51] J. Roggenbuck and M. Tiemann, "Ordered mesoporous magnesium oxide with high thermal stability synthesized by exotemplating using CMK-3 carbon," Journal of the American Chemical Society, vol. 127, no. 4, pp. 1096-1097, 2005.

[52] H. Yang, Q. Shi, B. Tian et al., "One-step nanocasting synthesis of highly ordered single crystalline indium oxide nanowire arrays from mesostructured frameworks," Journal of the American Chemical Society, vol. 125, no. 16, pp. 4724-4725, 2003.

[53] X. Lai, D. Wang, N. Han et al., "Ordered arrays of bead-chainlike $\mathrm{In}_{2} \mathrm{O}_{3}$ nanorods and their enhanced sensing performance for formaldehyde," Chemistry of Materials, vol. 22, no. 10, pp. 3033-3042, 2010.

[54] F. Jiao, J.-C. Jumas, M. Womes, A. V. Chadwick, A. Harrison, and P. G. Bruce, "Synthesis of ordered mesoporous $\mathrm{Fe}_{3} \mathrm{O}_{4}$ and $\gamma-\mathrm{Fe}_{2} \mathrm{O}_{3}$ with crystalline walls using post-template reduction/oxidation," Journal of the American Chemical Society, vol. 128, no. 39, pp. 12905-12909, 2006.

[55] E. Kang, S. An, S. Yoon, J. K. Kim, and J. Lee, "Ordered mesoporous $\mathrm{WO}_{3-X}$ possessing electronically conductive framework comparable to carbon framework toward long-term stable cathode supports for fuel cells," Journal of Materials Chemistry, vol. 20, no. 35, pp. 7416-7421, 2010.

[56] A. Rumplecker, F. Kleitz, E.-L. Salabas, and F. Schüth, "Hard templating pathways for the synthesis of nanostructured porous $\mathrm{Co}_{3} \mathrm{O}_{4}$," Chemistry of Materials, vol. 19, no. 3, pp. 485-496, 2007.

[57] H. Tüysüz, M. Comotti, and F. Schüth, "Ordered mesoporous $\mathrm{Co}_{3} \mathrm{O}_{4}$ as highly active catalyst for low temperature COoxidation," Chemical Communications, no. 34, pp. 4022-4024, 2008.

[58] R. Rossmanith, C. K. Weiss, J. Geserick et al., "Porous anatase nanoparticles with high specific surface area prepared by miniemulsion technique," Chemistry of Materials, vol. 20, no. 18, pp. 5768-5780, 2008.

[59] H. Xu, X. Liu, D. Cui, M. Li, and M. Jiang, "A novel method for improving the performance of $\mathrm{ZnO}$ gas sensors," Sensors and Actuators B: Chemical, vol. 114, no. 1, pp. 301-307, 2006.

[60] S. Yoriya and C. A. Grimes, "Self-assembled anodic $\mathrm{TiO}_{2}$ nanotube arrays: electrolyte properties and their effect on resulting morphologies," Journal of Materials Chemistry, vol. 21, no. 1, pp. 102-108, 2011.

[61] J. Qiu, M. Guo, and X. Wang, "Electrodeposition of hierarchical $\mathrm{ZnO}$ nanorod-nanosheet structures and their applications in dye-sensitized solar cells," ACS Applied Materials and Interfaces, vol. 3, no. 7, pp. 2358-2367, 2011.

[62] G. Wang, X. Shen, J. Horvat et al., "Hydrothermal synthesis and optical, magnetic, and supercapacitance properties of nanoporous cobalt oxide nanorods," Journal of Physical Chemistry C, vol. 113, no. 11, pp. 4357-4361, 2009.

[63] F. Cao, D. Wang, R. Deng et al., "Porous $\mathrm{Co}_{3} \mathrm{O}_{4}$ microcubes: hydrothermal synthesis, catalytic and magnetic properties," CrystEngComm, vol. 13, no. 6, pp. 2123-2129, 2011.

[64] N. D. Hoa and S. A. El-Safty, "Synthesis of mesoporous NiO nanosheets for the detection of toxic $\mathrm{NO}_{2}$ gas," Chemistry: A European Journal, vol. 17, no. 46, pp. 12896-12901, 2011.
[65] Y. Li, J. Xu, J. Chao et al., "High-aspect-ratio single-crystalline porous $\mathrm{In}_{2} \mathrm{O}_{3}$ nanobelts with enhanced gas sensing properties," Journal of Materials Chemistry, vol. 21, no. 34, pp. 12852-12857, 2011.

[66] Z. Zhong, J. Ho, J. Teo, S. Shen, and A. Gedanken, "Synthesis of porous $\alpha-\mathrm{Fe}_{2} \mathrm{O}_{3}$ nanorods and deposition of very small gold particles in the pores for catalytic oxidation of CO," Chemistry of Materials, vol. 19, no. 19, pp. 4776-4782, 2007.

[67] H. Nguyen and S. A. El-Safty, "Meso- and macroporous $\mathrm{Co}_{3} \mathrm{O}_{4}$ nanorods for effective VOC gas sensors," Journal of Physical Chemistry C, vol. 115, no. 17, pp. 8466-8474, 2011.

[68] T. Hyodo, N. Nishida, Y. Shimizu, and M. Egashira, "Preparation and gas-sensing properties of thermally stable mesoporous $\mathrm{SnO}_{2}$," Sensors and Actuators, B: Chemical, vol. 83, no. 1-3, pp. 209-215, 2002.

[69] T. Hyodo, S. Abe, Y. Shimizu, and M. Egashira, "Gas-sensing properties of ordered mesoporous $\mathrm{SnO}_{2}$ and effects of coatings thereof," Sensors and Actuators, B: Chemical, vol. 93, no. 1-3, pp. 590-600, 2003.

[70] Y. Shimizu, A. Jono, T. Hyodo, and M. Egashira, "Preparation of large mesoporous $\mathrm{SnO}_{2}$ powder for gas sensor application," Sensors and Actuators B, vol. 108, no. 1-2, pp. 56-61, 2005.

[71] M. Tiemann, "Porous metal oxides as gas sensors," Chemistry: A European Journal, vol. 13, no. 30, pp. 8376-8388, 2007.

[72] T. Waitz, B. Becker, T. Wagner, T. Sauerwald, C.-D. Kohl, and M. Tiemann, "Ordered nanoporous $\mathrm{SnO}_{2}$ gas sensors with high thermal stability," Sensors and Actuators, B: Chemical, vol. 150, no. 2, pp. 788-793, 2010.

[73] T. Waitz, T. Wagner, T. Sauerwald, C.-D. Kohl, and M. Tiemann, "Ordered mesoporous $\operatorname{In}_{2} \mathrm{O}_{3}$ : synthesis by structure replication and application as a methane gas sensor," Advanced Functional Materials, vol. 19, no. 4, pp. 653-661, 2009.

[74] X. Song, Z. Wang, Y. Liu, C. Wang, and L. Li, "A highly sensitive ethanol sensor based on mesoporous $\mathrm{ZnO}-\mathrm{SnO}_{2}$ nanofibers," Nanotechnology, vol. 20, no. 7, Article ID 075501, 5 pages, 2009.

[75] C. Cantalini, M. Post, D. Buso, M. Guglielmi, and A. Martucci, "Gas sensing properties of nanocrystalline $\mathrm{NiO}$ and $\mathrm{Co}_{3} \mathrm{O}_{4}$ in porous silica sol-gel films," Sensors and Actuators, B: Chemical, vol. 108, no. 1-2, pp. 184-192, 2005.

[76] J. Yang, K. Hidajat, and S. Kawi, "Synthesis, characterization and sensing properties of nano- $\mathrm{SnO}_{2}$ supported on SBA-15 as highly sensitive semiconductor gas sensors," Journal of Materials Chemistry, vol. 19, no. 2, pp. 292-298, 2009.

[77] N. D. Hoa and S. A. El-Safty, "Highly sensitive and selective volatile organic compound gas sensors based on mesoporous nanocomposite monoliths," Analytical Methods, vol. 3, no. 9, pp. 1948-1956, 2011.

[78] V. V. Sysoev, T. Schneider, J. Goschnick et al., "Percolating $\mathrm{SnO}_{2}$ nanowire network as a stable gas sensor: direct comparison of long-term performance versus $\mathrm{SnO}_{2}$ nanoparticle films," Sensors and Actuators B: Chemical, vol. 139, no. 2, pp. 699-703, 2009.

[79] H. V. Han, N. D. Hoa, P. V. Tong, H. Nguyen, and N. V. Hieu, "Single-crystal zinc oxide nanorods with nanovoids as highly sensitive $\mathrm{NO}_{2}$ nanosensors," Materials Letters, vol. 94, pp. 4143, 2013.

[80] J. H. He, C. H. Ho, C. W. Wang, Y. Ding, L. J. Chen, and Z. L. Wang, "Growth of crossed $\mathrm{ZnO}$ nanorod networks induced by polar substrate surface," Crystal Growth and Design, vol. 9, no. 1, pp. 17-19, 2009. 

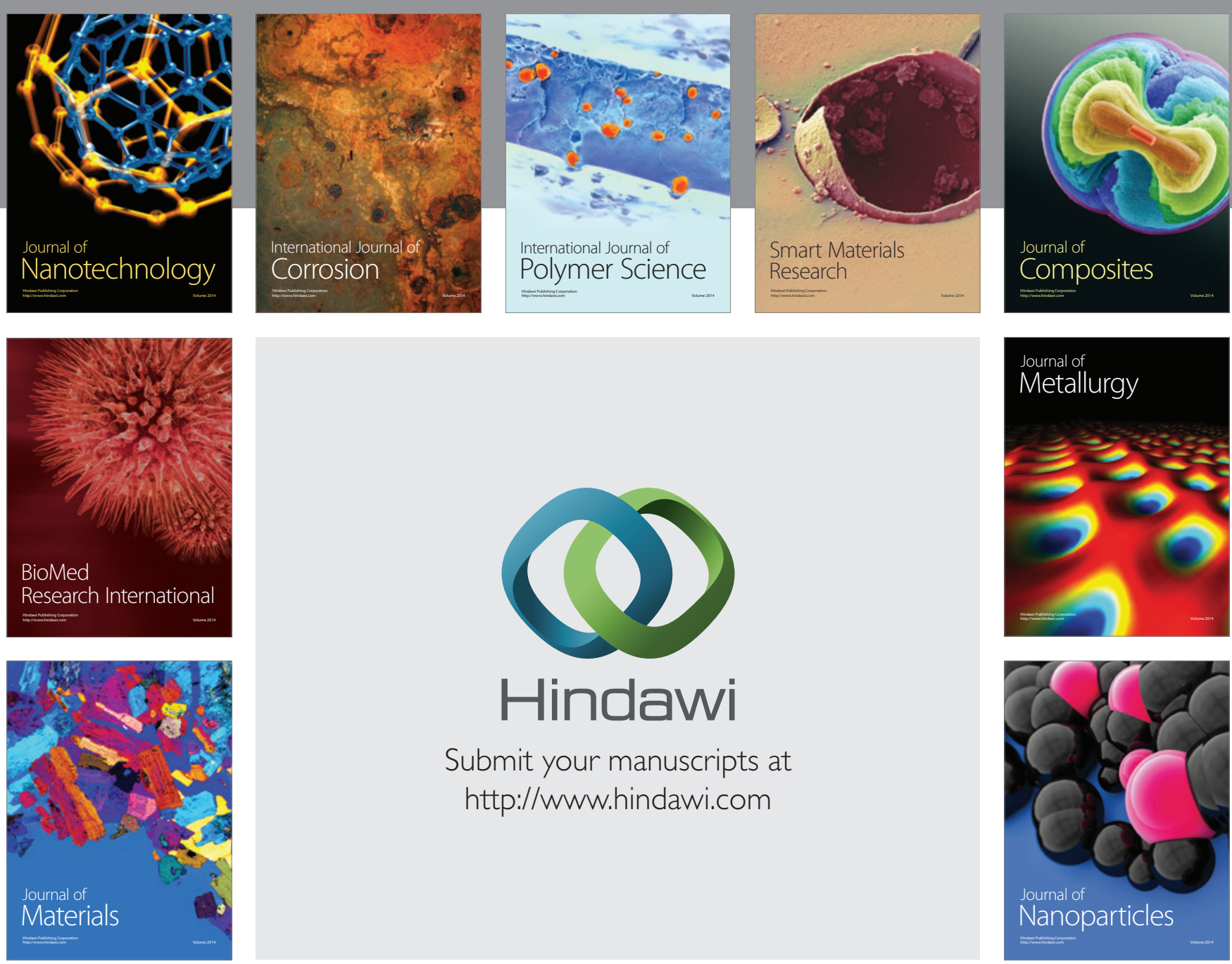

Submit your manuscripts at http://www.hindawi.com
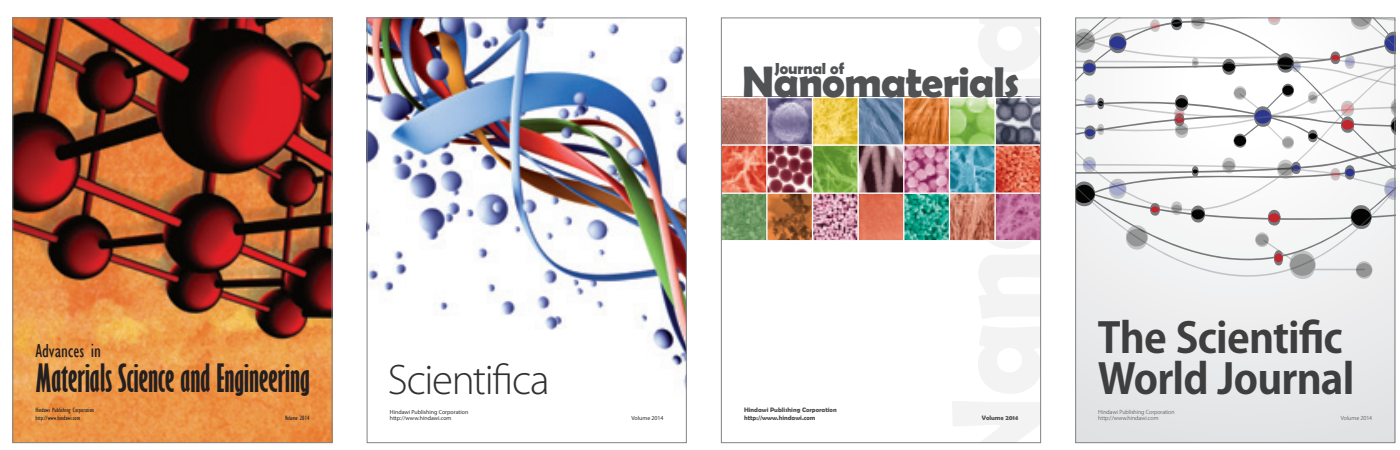

\section{The Scientific World Journal}
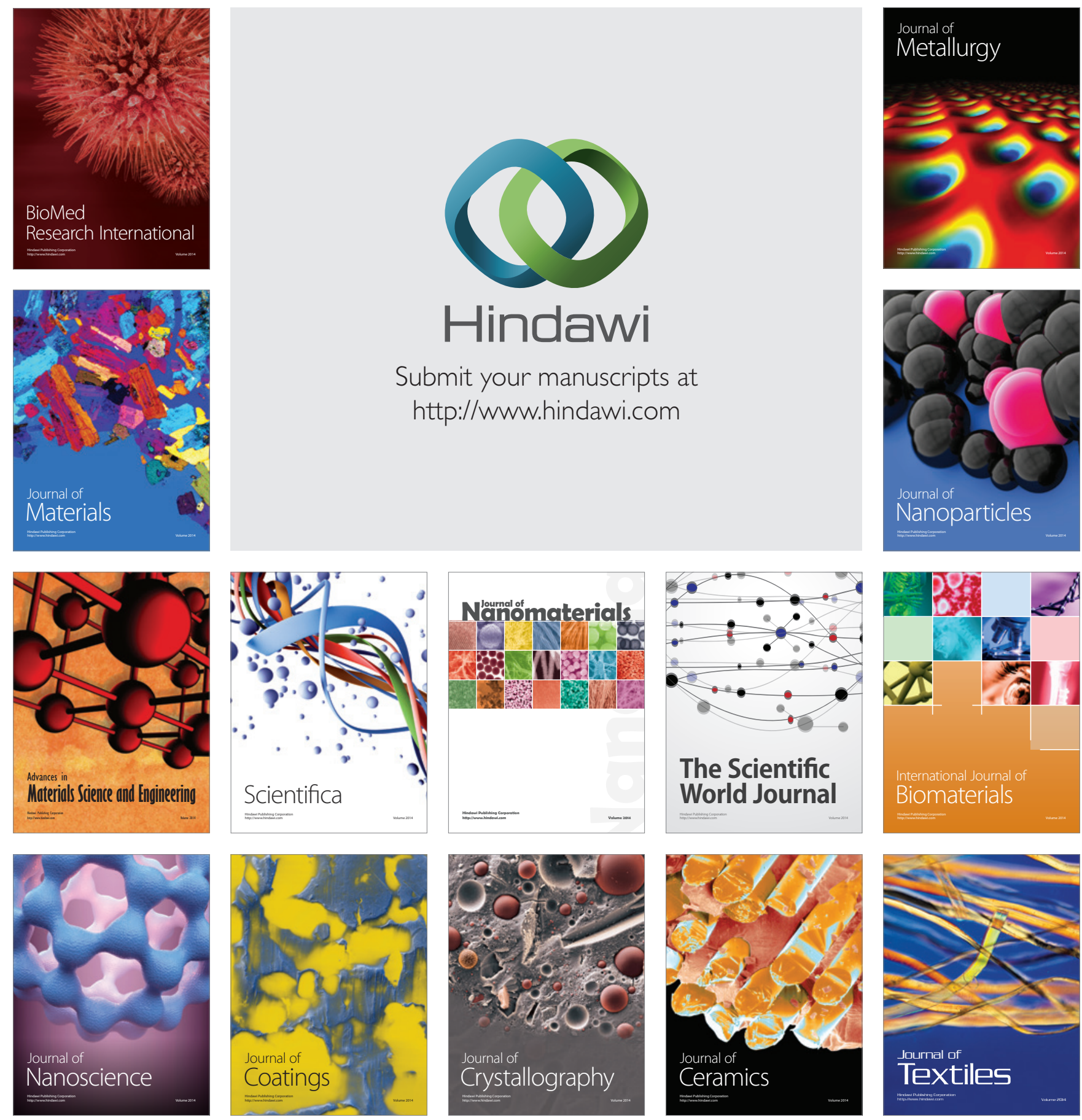